\title{
Culto y servicio amoroso a la Virgen en la Literatura medieval. El milagro del prometido de la Virgen y sus versiones hispánicas
}

\author{
Worship and Loving Service to the Virgin in Medieval Literature. \\ The Virgin's fiancé Miracle and its Hispanic Versions
}

\author{
Susana Macías Ávila \\ Investigadora independiente \\ smaciasster@gmail.com \\ Recibido: febrero de 2015. Aceptado: abril de 2015
}

\begin{abstract}
Resumen: El trabajo que aquí se presenta se centra en un género medieval, la literatura miraculística que tiene por protagonista a la Virgen María, y analiza comparativamente el denominado milagro del prometido de la Virgen, presente en numerosas compilaciones europeas y, concretamente, en tres colecciones hispánicas escritas en lengua castellana, galaico-portuguesa y catalana.
\end{abstract}

Palabras clave: literatura miraculística, milagro del prometido de la Virgen, Gonzalo de Berceo, Alfonso X el Sabio, Miracles de la Verge María, Cantigas de Santa María, Milagros de Nuestra Señora.

\begin{abstract}
This article looks at some of the studies focused on a medieval gender, Virgin Mary's miracula, and analyzes comparatively the so-called Virgin's fiancé miracle present on numerous European compilations and specifically in three Hispanic collections written in Spanish, Galician-Portuguese and Catalan.

Keywords: miracula, Virgin's fiancé miracle, Gonzalo de Berceo, Alfonso X el Sabio, Miracles de la Verge María, Cantigas de Santa María, Milagros de Nuestra Señora.
\end{abstract}

La literatura miraculística ha merecido escasos estudios en los últimos años, pero se trata de un género medieval, reflejo del pensamiento y la sociedad de aquella época, que interesó a los investigadores en el siglo XIX y hasta, aproximadamente, mediados del XX. Este artículo retoma esa línea de investigación y se centra en el análisis del denominado milagro del prometido de la Virgen en tres versiones distintas de este relato, escritas en otras tantas lenguas hispánicas: cas- 
tellana, catalana y galaico-portuguesa. Hacer patentes sus características, similitudes y diferencias, y poner el foco en los ejemplarios catalanes, que adolecen de suficientes estudios críticos, forman parte de los objetivos de este trabajo.

El milagro que aquí nos ocupa está presente en dos de las colecciones marianas más conocidas y reconocidas escritas en nuestra Península, Milagros de Nuestra Señora (MdeNS), de Gonzalo de Berceo, y Cantigas de Santa María $(C S M)$ de Alfonso X el Sabio, y en una tercera compilación, leridana, infinitamente menos difundida y escrita en catalán, Miracles de la Verge Maria (Miracles a y Miracles $b$ ). Hemos comparado estas tres versiones entre sí y con otras extraídas de diversas colecciones europeas, pues es sabido que la creación medieval poco, o más bien nada, tiene que ver con el actual concepto de originalidad y que los autores tienden a recrear modelos que consideran valiosos y relevantes. Estos escritores-compiladores buscaron subirse a los hombros de los gigantes clásicos, reelaboraron sin descanso las fuentes latinas, las combinaron con cuanto tuvieron a su alcance -cuentos orientales, himnos bíblicos, historias celtas-, y repitieron una y otra vez la fórmula hasta hacerla propia, asimilarla, y legarnos los ecos del relato original.

En busca de esa historia primigenia, tratamos de comparar cada texto con sus coetáneos y con versiones de otras épocas para saber lo que cada autor crea o recrea. Como señala Reinaldo Ayerbe-Chaux (1975: XIV), «la obra literaria de la Edad Media es esencialmente una obra de compilación de materiales ya existentes que se organizan en formas diversas y se pasan a la posterioridad», pero creemos, también con este investigador, que autores como Berceo, Alfonso X o Gautier de Coinci no son meros copistas. Dice Ayerbe-Chaux (1975: XVI): «Es absurda la sistemática falta de fe en el poder creador de los autores medievales y aseverar a cada paso que pudo haber existido alguna versión más cercana a la forma que el escritor nos brinda, tratando así de descartar la existencia del genio creador».

Por ello, este trabajo es eminentemente comparativo con el fin de descubrir cuánto deben los milagros analizados a sus fuentes y cuánto a la creación. Tomando como modelo los estudios de Ayerbe-Chaux, se han confeccionado unos cuadros, que se adjuntan al final de este trabajo, en los que se comparan determinados elementos de las distintas versiones del milagro del prometido de la Virgen. Cotejamos elementos que se perfilan como constantes en las diferentes versiones de ese milagro o que son originales de una versión en particular: personajes y caracterización de los mismos, símbolos, referencias geográficas, elementos mágico-milagrosos... En esos cuadros se incluyen las referencias de los catálogos de autores como Frederic C. Tubach, Antti Aarne, Stith Thompson o Harriet Goldberg, que confeccionaron índices de tipos y motivos literarios, un esfuerzo titánico destinado a clasificar miles de relatos breves.

\section{TEOLOGÍA Y LITERATURA MARIANAS: EL DESPERTAR DE LA PASIÓN POR LA VIRGEN}

El género miraculístico participa de lo religioso y didáctico, lo moralizante o doctrinal, lo épico, laudatorio e, incluso, lo maravilloso, de modo que en oca- 
siones conserva significativas vecindades con otros géneros (hagiografía, sermón, himno, cuento, cantar de gesta ${ }^{1} \ldots$..) cultivados asimismo en este momento de gestación de las lenguas y las literaturas romances, durante la Baja Edad Media. Juan Manuel Rozas (1976: 18) define el milagro como «una variante del género cuento» emparentada con los exempla y la literatura hagiográfica, y lo considera narración corta de un hecho maravilloso, con un sentido cristiano de los mirabilia frente a la magia pagana. Para Rozas (1976: 15-16), María, la heroína de estos relatos breves, es, además, el elemento temático unificador de los mismos: «Parece a simple vista obvio indicar que la Virgen, la Gloriosa, es el centro significativo y el personaje que da unidad a priori a todos los milagros [...]. El asunto es aquí la teología mariana».

Por ello, preguntarnos por el origen de ese mito llamado María, un personaje que en los relatos bíblicos apenas se dibuja, parece en este punto pertinente, ya que dio lugar a la gestación de esa teología mariana ${ }^{2}$ e, incluso, de un género literario con características propias. La literatura mariana, que vivió su momento de apogeo en los siglos XII-XIII, así como su declinar a partir del XV, forma parte de la expresión de una nueva religiosidad, más íntima y cercana, que humaniza a las personas divinas y que se manifiesta en la devoción popular bajo la influencia de la espiritualidad cisterciense y de las nuevas órdenes, en especial, de la sensibilidad franciscana. Esta orden mendicante difunde en el Trecento italiano una humanísima imagen mariana, la de la Virgen de la Humildad, figura sedente que amamanta a su Hijo y que se relaciona con la advocación de origen bizantino de la Virgen de la Leche. Pero para Marina Warner (1991: 182), se debe, sin embargo, al cisterciense Bernardo de Claraval el despertar en Occidente de la pasión por la Madre de Dios:

El amor intensamente personal a la Virgen que brotaba del corazón de san Bernardo infundió después de él en su culto la misma agitada e íntima dulzura. Su elocuencia acerca del Cantar [de los Cantares], la Anunciación y la Asunción marca el fulcro de la devoción a la Virgen en Occidente. Hasta ese momento, era una figura majestuosamente remota, utilizada para definir las complejidades de la doctrina cristológica, o para simbolizar la autoridad de la Iglesia. Hubo muy poca devoción personal hacia ella en Occidente, y su culto, en términos de plegarias, procesiones y fiestas, solo configuraba un tranquilo

\footnotetext{
1 Teresa Labarta (Berceo 1990:19) define la Vida de Santo Domingo, de Gonzalo de Berceo, como «un cantar de gesta a lo divino».

2 El artículo de Albert Hauf (2015) repasa buena parte de la bibliografía reciente y clásica en torno al despertar de ese interés y devoción encendidos por la Virgen en los siglos XII-XIII en Occidente. Entre los títulos más recientes se encuentran los siguientes: Boss, S. J., «The Development of the Virgin's Cult in the High Middle Ages» y Voscher, E., «Marian Devotion in the Latin West in the Later Middle Ages», en Beattle, T. + Boss, S. J. (eds.) (2007) Mary: The Complete Resource, Oxford, Oxford University Press, pp. 149-170 y 171-201, respectivamente, así como Reynolds, B. K. (2012) Gateway to Heaven. Marian Doctrine and Devotion. Image and Typology in the Patristic and Medieval Periods, vol. I, Nueva York, New City Press y Rubin, M. (2009) Mother of God. A History of the Virgin Mary, New Haven, Yale University Press. Entre las obras clásicas, Graef, H. (2009) Mary. A History of Doctrine and Devotion, Indiana, Ave Maria Press (la $1 .^{\text {a }}$ ed. es de 1963-1965).
} 
acompañamiento a los grandes misterios del año cristiano. En el siglo $\mathrm{X}$ comenzaron los primeros movimientos de adoración que transformaron a la Virgen de una reina distante en una madre misericordiosa y amable, «Nuestra Señora», la que inspira amor y alegría, la amiga íntima de monjes y predicadores, y la más prominente figura de la jerarquía cristiana.

Con san Bernardo culmina ese proceso de siglos en el que la reverencia servicial da paso a la confianza y, finalmente, al puro amor. Con él, dice Isabel Uría (Berceo 1997: XX), «el servicio amoroso a la Madre de Dios [que surge en ámbitos monásticos en torno al siglo $\mathrm{X}$ ] alcanza su expresión más emotiva, tierna y afectuosa». Todo ello coincide con una evolución de la religiosidad hacia formas cada vez más humanizadas, que alcanza su culmen en el siglo XIII. Es la época en la que cristalizan las más conocidas invocaciones a la Virgen (Salve Regina, Memorare de san Bernardo, Ave María, el Rosario...), un momento de expansión de la iconografía mariana, sus advocaciones y su liturgia, de la erección de catedrales, iglesias y capillas consagradas a su nombre, y de una eclosión de obras musicales y literarias que tienen a la Virgen como eje temático.

\section{FIN'AMORS Y SERVICIO AMOROSO A LA VIRGEN}

Los siglos XII y XIII son también los de la fin'amors que la literatura provenzal exporta a los ambientes cortesanos europeos. Esa corriente mundana acaba salpicando la literatura religiosa, el género miraculístico y, en particular, el milagro que ocupa la parte central de este artículo, el llamado milagro del prometido de la Virgen, protagonizado por un clérigo o por un caballero, dependiendo de las versiones, que desiste de contraer matrimonio para entregar su vida al servicio de la Reina del cielo. Nos interesa este milagro porque creemos que en él confluyen algunos elementos característicos de esta época: la concepción de lo maravilloso cristiano, un sentido del humor del que puede que no estemos tan alejados, pero sobre todo, el culto mariano y el amor cortés, eso sí, a lo divino, expresado en estos milagros como servicio amoroso a la virgen María, a la señora celestial, en lugar de a la dama terrenal. José Aragüés (2014: 97) coincide en subrayar «la convergencia entre la idealización de la mujer propia de la poesía trovadoresca y la intensificación del culto mariano en la época, fenómenos nutridos por un compartido léxico cortés», en algunos de estos relatos medievales. Aragüés analiza y compara dos historias que mezclan elementos hagiográficos y caballerescos, la cantiga XVI de Alfonso X, en la que un caballero reza 200 Avemarías para lograr el amor de una dama y acaba enamorándose de la Virgen, y el cuarto relato del Llibre d'Ave Maria de Ramon Llull, que tiene por protagonista a un caballero que decide convertirse en servidor de la Virgen y olvidar su mundano amor después de que un abad le convenza de que la Madre de Dios es la mejor y más bella señora que un caballero pueda servir.

Por su parte, en el milagro del prometido de la Virgen se cumple con rigurosa fidelidad, y se podría decir que por partida doble, lo que señala Warner (1991: 145): «María, en la Edad Media, se convierte en sujeto de amor poético». Decimos doblemente, porque la Virgen, como protagonista y, de algún 
modo, destinataria de las colecciones de milagros, es Sennor a la que los autores pretenden trovar, como Alfonso X declara en el prólogo B de sus $C_{S M}{ }^{3}$, y porque María actúa, en este milagro concreto, como mujer que es amada y reclama, celosa y coqueta, el amor de su entendedor, según el código cortés de la época. Este milagro da la medida de hasta qué punto el culto mariano se concebía entonces en términos humanos, porque la Virgen aparece con atributos y características femeninos, y porque el amor de María y el clérigo se describe mediante un lenguaje feudo-vasallático.

Hemos señalado un poco más arriba que san Bernardo contribuyó a propagar el culto a la Virgen en la Edad Media, pues desarrolló todo un sistema místico por el que los cristianos son transfigurados por el Amor. En él, Cristo es el amante del Cantar de los Cantares y la novia es la Iglesia, el alma, los monjes de Claraval, los cristianos..., pero también la Virgen comenzó, gracias a la literatura miraculística, a formar parte de esa ecuación que involucra amorosamente a seres divinos y mortales. Alicia Ferraresi (1976: 26) explica cómo se hizo verbo este sistema:

Para hablar de amor a un Dios que es Amor, el alma cristiana tuvo que hacerlo en el lenguaje que desde siempre había expresado la experiencia amorosa. El Cantar de los Cantares se volvió alegoría religiosa -el diálogo enamorado de la Iglesia o del alma con Dios-, y así toda la ingente riqueza de sus metáforas eróticas se hizo alimento perenne de la mística cristiana. La unión del alma con su Amado no podía encontrar otra figura, en la experiencia humana, que la unión amorosa de hombre y mujer. Durante casi toda la Alta Edad Media el antiguo lenguaje del amor secular fue usado «a lo divino» hasta que, cuando renació la poesía culta en Europa, muchas de las palabras clave se habían vuelto ya inseparables de su connotación religiosa. Por eso, «no solo el lenguaje amoroso, sino precisamente el tipo de lenguaje amoroso más en consonancia con el amor courtois, había ido acumulándose, durante siglos, en la tradición mística y teológica» (Dronke 1965: 62). No podría volver a ser secularizado jamás.

La amada, «hortus conclusus» ${ }^{4}$, aparece por primera vez en el Cantar de los Cantares, que toma de la literatura erótica sus más sorprendentes y audaces imágenes. El refrán «Rosa das rosas e Fror das frores, / Dona das donas, Sennor das sennores» de la cantiga número $\mathrm{X}$ de Alfonso $\mathrm{X}$ hunde sus raíces en esa metáfora bíblica, aunque antes ha sufrido transformaciones e influencias, porque, en el camino, las fórmulas acuñadas y perpetuadas por la literatura religiosa han sido de nuevo adoptadas por la erótica profana y adaptadas al lenguaje del amor cortés para después regresar al ámbito espiritual en un viaje de ida y vuelta que hace difícil saber qué engendró qué.

${ }^{3}$ Canta Alfonso X (1986: vol. I, pp. 54-56) a la Virgen: «E o que quéro é dizer loor / da Virgen, Madre de Nóstro Sennor, / Santa María [...] Ca o amor desta Sennor é tal, / que queno á sempre per i mais val».

${ }^{4}$ Cantar de los Cantares (IV, 12-13) dice: «Eres jardín cercado, hermana mía, esposa, / eres jardín cercado, fuente sellada». 
Para Isabel Uría (Berceo 1997: XXIII), el culto a la Virgen influyó en el nacimiento y desarrollo de la lírica del amor cortés en los siglos XI-XIII a través de la devotio Mariae de monjes y clérigos: «El caballero, siguiendo el código del amor cortés, rinde servicio a la domna y se declara su «vasallo» y su «siervo» para servirla y complacerla, de la misma manera que los devotos de Nuestra Señora se llamaban siervos y vasallos de María (famulus, servus, mancipium) y, en sus plegarias, hablan del «ardiente amor de siervo».

Sin embargo, desde la segunda mitad del siglo XII se observa una nueva vuelta de tuerca: la Señora celestial desplaza a la terrena en la lírica occitana. El culto mariano llega a su culmen, y los poetas vuelven a lo divino las fórmulas poéticas de los cantos de amor humano. Según explica Uría (Berceo 1997: XXIII), «estas expresiones, al ser aplicadas por los trovadores a Nuestra Señora, se espiritualizan -si es que no lo estaban ya-, de manera que los devotos de la Gloriosa pueden usarlas sin reparos para dirigirse a la Virgen María. Eso hicieron Gautier de Coinci, Gonzalo de Berceo y Alfonso X». Los poetas de la fin'amors cambiaron su objeto amoroso, pero no su lenguaje.

Las interacciones entre el amor cortés y la devoción mariana, entre la literatura religiosa y la amorosa, fueron tan frecuentes y recíprocas durante siglos que se hace imposible deslindarlas y señalar qué influyó antes en qué. Wyrembek y Morawski (1934: 30) explican el sentido y las razones de ese préstamo, evidente en el milagro del prometido de la Virgen: «Sans doute, dans leurs descriptions de la Vierge, ces auteurs s'inspirent-ils de la littérature courtoise, des chançons et des lais profanes. Mais s'ils s'en inspirent c'est pour réagir contre le divinisation de la femme du monde dans la poésie lyrique et dans la fantasmagorie bretonne».

Se podría afirmar que narrar los milagros, las hazañas de la Virgen en favor de sus siervos, es una forma de exaltación y de alabanza a la Madre de Dios, y ello, sin duda, es un servicio amoroso a María, la Señora a la que Berceo, Alfonso $\mathrm{X}$ y el escritor anónimo de los milagros en prosa catalana editados por Pere Bohigas (Miracles a) y por Antoni Parramon (Miracles $b$ ) pretenden cantar. Los Milagros de Nuestra Señora, las Cantigas de Santa María y la colección mariana del Archivo de Lérida están escritos bajo la influencia de esa especial forma de concebir la devoción a la Virgen que san Bernardo desarrolló conceptualmente. De ahí, la obsesiva confesión del propósito de Alfonso X (1986: vol. 1, 54-56) de trovar a la Madre de Dios en el prólogo B de sus Cantigas. El propio Berceo habla de un servicio cortés a la Virgen: «Todo omne del mundo fará gran cortesía / qui fiziere servicio a la Virgo María: / mientre que fuere vivo verá plazentería, / e salvará la alma el postrero día» (MdeNS, 115). A continuación, concretaremos cómo la leyenda del prometido de la Virgen traslada al plano divino los conceptos de servicio amoroso y amor cortés de la época.

\section{EL MILAGRO DEL PROMETIDO DE LA VIRGEN}

Las tres colecciones mencionadas más arriba recogen el milagro del prometido de la Virgen, que, según Wyrembek y Morawski (1934: 1), es «un des chapitres les plus intéressants et les plus typiques de la geste thaumaturgique de Notre 
Dame». Fue Adolf Mussafia quien, en sus Studien zu den mittelalterlichen Marienlegenden (1887-1891), adjudicó a estos relatos el nombre genérico de milagros del prometido de la Virgen (Marienbräutigam). Esta historia se repite en colecciones latinas y vernáculas, y siempre gira en torno a una idea (el compromiso, los esponsales con la Reina celestial) que se desarrolla como sigue: la Virgen se aparece (en sueño, en visión, en forma de estatua) a su elegido y le exhorta a mantenerse casto y a consagrarse a su servicio. La idea de los esponsales místicos está ya prefigurada, como hemos apuntado, en el Cantar de los Cantares, pero en los siglos XII y XIII, época de apogeo del culto mariano, es la Virgen -y no Dios- la persona divina con la que se promete un mortal. Dicen Wyrembek y Morawski al respecto (1934: 23-24): «De l'idée de l'épouse de Dieu à celle de l'époux ou du fiancé de la Vierge il n'y avait qu'un pas. On a tout simplement transposé le motif des épousailles mystiques avec Dieu sur Marie. A l'époque du culte fervent de Notre Dame, cette transposition n'a rien d'étonnant».

Según recuerdan Wyrembek y Morawski (1934: 1), Poncelet cita, en su Index miraculorum B. Virginis Mariae, ocho versiones de este milagro arquetípico, que, a su vez, divide en tres grupos, según sea el personaje principal un clérigo, un caballero (que reza Avemarías para enamorar a una dama y se desposa finalmente con la Virgen) o un joven (prometido a una imagen de Nuestra Señora). Las tres versiones hispanas que analizamos, el milagro XV de la obra de Berceo Milagros de Nuestra Señora, la cantiga CXXXII de la colección de Alfonso X y el relato XII de la compilación anónima catalana Miracles de la Verge Maria, pertenecen al primer grupo descrito por Poncelet, el más célebre y difundido, que tiene por protagonista a un clérigo, aunque las relaciones con los otros dos son claras, como veremos.

Poncelet asignó el número 866 a todos los relatos protagonizados por un clérigo de Pisa y el 964 a todas las historias protagonizadas también por un clérigo, aunque en este caso hijo del rey de Hungría. Se especifica claramente que el clérigo es de Pisa en los milagros de Berceo y Alfonso X, mientras que el relato leridano se ajusta más al segundo caso: es hijo de rey y reina, aunque no existe referencia geográfica alguna. En versiones posiblemente anteriores a las del clérigo de Pisa y derivadas de una homilía de Beda, según Wyrembek y Morawski (1934: 3), los hechos no tienen lugar en Pisa, sino en Roma. En el caso de las versiones protagonizadas por un clérigo, hijo (a veces, hermano) del rey de Hungría, los hechos narrados se relacionan frecuentemente con la fiesta de la Inmaculada Concepción. Sea como fuere, todas las versiones de este milagro se refieren de una u otra forma a la virtud de la castidad.

En palabras de M. ${ }^{a}$ Jesús Lacarra (1999: 296), «se trata de una interesantísima historia que encadena materiales folclóricos, clásicos, postclásicos y medievales, sin que resulte fácil delimitar exactamente cuál fue su origen». La versión más antigua de este milagro, con materiales de origen romano, es la historia de un joven prometido a una imagen de piedra y fue recogida por William of Malmesbury (1840: 354-357) en su De gestis regum anglorum hacia 1125. La inclusión de este relato a mediados del siglo XII en el Speculum historiale de Vincent de Beauvais le valió una amplia difusión. A partir de él, se recogió, entre otras colecciones, en el Speculum laicorum, la Scala Coeli, la Leyenda Áurea, 
el Alphabetum narrationum y su versión catalana, el Recull d'exemples. Mucho más recientemente, en el siglo XIX, inspiró a Próspero Merimée su Venus d'Ille, la versión contemporánea más conocida. En todas ellas, una estatua se convierte en amante o novia de un mortal, y Harriet Goldberg cataloga este motivo con dos referencias distintas: la T299.3, en la que se relata el caso de un joven que comienza a sufrir impotencia al colocarle un anillo a una estatua de Venus, y la T376, que narra la historia de un muchacho que queda comprometido con la Virgen al poner un anillo en la mano de la imagen de la Madre de Dios. Según Goldberg, la historia del clérigo de Pisa sería una variante de esta última y recibe el número de catalogación T376.1 en su índice de motivos.

Todas estas historias que derivan, más o menos directamente, del relato de Malmesbury tienen un origen pagano, pero muchas fueron cristianizadas, reformuladas e incluidas en mariales y colecciones de exempla al sustituir a la diosa pagana protagonista por la virgen María. «Cette substitution n'est pas sans produire un effet des plus grotesques», señalan Wyrembek y Morawski (1934: 17). Era difícil imaginar que Venus, caracterizada en estos relatos como una mujer que viste ropajes de burdel, podría transformarse en la Sin Mancha. Aunque esta transposición no tuviera, sin duda, intención humorística alguna, hoy resulta chocante. Otros pasajes de estos relatos tienen, sin embargo, la clara intención de provocar hilaridad. Así, en el milagro XV de Berceo, el novio desaparece en su noche de bodas por arte de magia y deja a su mujer abrazando el aire; y en otras versiones que analizaremos a continuación, un recién casado cree estar ante un fantasma al escuchar una voz que le recrimina su infidelidad y no ver a nadie en la habitación.

Jaime Asensio (1985) compara en un estudio, en el que rinde homenaje a Alfonso X en el sexto centenario de su muerte, la mencionada obra de Mérimée y la cantiga XLII del rey Sabio, teniendo en cuenta la evidente diferencia del carácter cristiano del relato medieval y pagano del decimonónico. Según Keller (1959: 458), «King Alfonso's version of the motif of the statue is unique in Spain and Portugal», aunque la existencia del eximpli 650 perteneciente a la traducción catalana de la compilación de Arnau de Lieja viene a matizar tal afirmación. La Virgen, a quien Alfonso X hace protagonista de la cantiga frente a la Venus pagana del cuento de Mérimée, obra el milagro de la conversión final del joven, que se retira del mundo, mientras que el autor francés, con el concurso de una suerte de magia pagana, precipita a los personajes hacia un desenlace fatal. La reprimenda de María al joven de la cantiga es abrazo mortal en el relato decimonónico. Asensio percibe, con todo, tres elementos comunes en ambas:

- La estatua, que en ambos relatos es removida para acercarla a los hombres y que estos puedan contemplar su belleza. En el milagro de Alfonso X, la Virgen se traslada del altar a los soportales de la iglesia durante unas obras; en el relato de Mérimée se desentierra y se coloca en el jardín de la familia protagonista.

- El anillo, símbolo de la atadura, que los prometidos en matrimonio y protagonistas de ambos relatos colocan en la mano de las respectivas estatuas para evitar que se deterioren o pierdan mientras juegan a la pelota. Cuando la Virgen y Venus cierran sus manos, el vínculo entre inmortal y humano se torna indestructible y el destino del amante, que no puede recuperar el anillo, se 
cierra. Según Wyrembek y Morawski (1934: 12-13), el anillo, que, en los cuentos populares, suele tener un poder mágico, en textos de carácter didáctico-religioso, es símbolo de fe en ocasiones, talismán contra las tentaciones carnales en otros casos, y signo de esponsales místicos, de «indissoluble union avec la Reine céleste». Este último es el caso que nos ocupa.

- La promesa. Asensio sobreentiende que la que el joven de la cantiga XLII le hace a la Virgen ${ }^{5}$ está también en la simple entrega del anillo, en las ofrendas que eleva el padre del novio a la estatua o en el discurso que aquel pronuncia en el banquete nupcial del relato de Merimée (2005: 29):

Qu'est-ce donc, mes amis? Le vin que j'ai bu me fait-il voir double? Il y a deux Vénus ici [...] L'une, je l'ai trouvée dans la terre comme une truffe; l'autre, descendue des cieux, vient de nous partager sa ceinture [...] Mon fils, choisis de la Vénus romaine ou de la catalane celle que tu préfères. Le maraud prend la catalane, et sa part est la meilleure. La romaine est noire, la catalane est blanche. La romaine est froide, la catalane enflamme tout ce qui l'approche.

La promesa es tan firme que, en ambos relatos, las estatuas se interponen entre el joven y su mujer en la cama, e impiden que la vida marital prosiga. Por eso, en la cantiga XLII, los testigos de los hechos aconsejan al joven que profese en un monasterio «de Claraval».

Alfonso $\mathrm{X}$ introduce en su relato un elemento de gran trascendencia, que distingue esta versión: el sueño. La Virgen no se aparece al beneficiario del milagro mientras reza en la iglesia, como sucede, por ejemplo, en el milagro XV de Berceo, sino que se muestra al joven en un sueño. Alfonso $X$ habla de los sueños en su Setenario y, siguiendo una corriente especulativa que se pierde en la más remota Antigüedad, los considera uno de los medios a través de los que la divinidad se hace presente y se comunica con el hombre. En la Ley XVI del Setenario (1945: 48), lo define como un tiempo de descanso de los trabajos que el hombre hace durante la vigilia. Sin embargo, el rey mantiene que, mientras eso ocurre, «el spíritu de la vida mueue los sentidos e quiere obrar con ellos bien commo ssi estudiesen despiertos». Existe, en esos momentos, una conexión espiritual con lo trascendente. Alfonso X renuncia a que la Virgen aparezca en una visión, quizá por el negativo concepto que de la misma tiene, según explica en la Ley XVII de la mencionada obra (1945: 48-49): «los que asacauan creencias e ssectas e opiniones de tales visiones commo ésta, bien se puede entender que non era rraygado el ssuenno donde tal creencia sse mouye nin podríe sser ffirme ninguna cosa que ssobre tal rrazón ffuesse».

Setecientos años separan las versiones comparadas por Asensio, pero las coincidencias son evidentes y delatan un hilo que aparece, desaparece, pero no se interrumpe desde la Edad Media hasta nuestros días.

5 «E os gollos ficados ant'ela con devoçon, / dizendo «Ave María», prometeu-lle log'enton / que des ali adelante nunca no seu coraçon / outra moller ben quisesse e que lle fosse leal» (CSM XLII, vv. 49-52). 
Próximos al cuento decimonónico de Mérimée y, sobre todo, a la cantiga alfonsina están otros relatos que Poncelet clasifica con el código 1489, historias en las que el protagonista coloca también un anillo en el dedo de una estatua de la Virgen. Pueden parecer muy distintos de los relatos hispánicos que son objeto de este artículo, pero tienen un tronco común. La primera de las versiones del anillo a la que nos referiremos es la que M. Tarayre (1999: 54) entresaca del libro séptimo del Speculum historiale de Vincent de Beauvais (milagro 87). Un grupo de «pueri clerici» juega a la pelota ante una iglesia, y uno de ellos, que lleva el anillo que le ha dado una joven, «carnali amore ducta», entra en la iglesia para guardarlo hasta que acabe el juego. Dentro encuentra una imagen de la Virgen y, «admirans eius pulchritudinem», coloca el anillo en la mano de la estatua al tiempo que se promete a ella con esta fórmula: «Vere in omnibus formosior, et illa etiam quae mihi hunc anulum amoris munere condonauit, ideoque eo renuncio teque deinceps amare et tibi servire decerno, ita dumtaxat, ut ego uice reddita amoretua dignus inueniar». Dicho esto, la estatua cierra su mano impidiendo que el anillo le sea arrebatado. El joven, estupefacto, llama a sus compañeros y les cuenta lo sucedido. Impresionados por el relato, estos le aconsejan «saeculo renunciare» y convertirse en siervo de la madre de Dios. El chico decide, sin embargo, casarse poco después. Pero en su noche de bodas, la Virgen se aparece y se coloca entre el clérigo y su mujer, reprochándole su infidelidad. El joven palpa a su alrededor, pero no encuentra nada. Cree haber oído la voz de un fantasma. La reprimenda de la Virgen continúa, por lo que el clérigo decide renunciar a todo lo que tiene esa misma noche e ingresar en una orden para servir de por vida a la Señora celestial.

Las circunstancias de este relato son muy diferentes a las del milagro del clérigo de Pisa o del hijo del rey de Hungría, cuyas versiones hispánicas analizaremos finalmente, pero este puer clericus también se ha enamorado de la Virgen, y esta tendrá que aparecérsele para lograr que el joven se le entregue. Hasta aquí lo que de común tienen los relatos catalogados con los códigos 866 (milagros del clérigo de Pisa) y 1489 (milagros del anillo) por Poncelet. Comparten elementos, pero sus significados difieren. Por ejemplo, lo que, en los cuadros de los Anexos, hemos denominado mundo existe en ambos grupos de milagros, pero actúa en sentidos opuestos. Mientras que los parientes y amigos del clérigo de Pisa le aconsejan separarse de la Virgen y disfrutar del mundo, aquí los compañeros de juego del protagonista le aconsejan renunciar a las vanidades y profesar. Es el joven del anillo el que se inclina por la concupiscencia y el mundo, mientras que el de Pisa se ve obligado a aceptar, ante la insistencia o por la violencia, el destino que le marcan familiares y amigos.

En ambos relatos, la Virgen se aparece al protagonista, pero lo hace en momentos diferentes. En las historias del clérigo de Pisa, la aparición tiene lugar normalmente mientras reza antes de la boda, y eso provoca que, en algunos casos, esta no llegue a celebrarse, aunque el hecho de que el protagonista se enfrente a su noche de bodas resulta, a la postre, un acierto narrativo, ya que agranda su virtud al vencer la tentación o enfatiza la actuación milagrosa de la Virgen, dependiendo del mayor o menor realismo de cada relato. En las historias del anillo, la boda siempre tiene lugar, y es esa noche cuando se produce la aparición, con lo que la escena culminante se retrasa y se aproxima al desenla- 
ce, que se produce inmediatamente después de ese momento álgido. El peso del relato bascula y la estructura, por tanto, varía. Además, en las historias del joven del anillo, la visión de la Virgen tiene lugar dentro de un sueño, como en las cantigas XLII y CXXXII de Alfonso X.

Por otra parte, los elementos simbólicos de las versiones del anillo son más numerosos e interesantes: la estatua que cobra vida y enamora a un mortal, un tópico literario que se remonta al mito griego de Pigmalión; el símbolo del anillo, que sella la unión; y la promesa indisoluble pronunciada ante la estatua, que recuerda a los conjuros mágicos de los cuentos folklóricos. Estos tres elementos, de los que ya hemos hablado más arriba al comparar la cantiga XLII y el cuento de Mérimée, convierten estas narraciones en relatos de transición entre el original pagano y las versiones, más cristianizadas y menos maravillosas (en el sentido de los cuentos populares), del clérigo de Pisa.

El milagro 650 de la traducción en lengua catalana de la colección de Arnaldo de Lieja sigue más de cerca que la versión de Beauvais el supuesto original romano, pues el propio autor atribuye la historia a «Guillelmus» (Malmesbury) en el título y sus elementos paganos son evidentes. Los hechos suceden, como en el relato de Malmesbury, en Roma y el protagonista es un «jove qui novellament havie pres muller» y que «jugaba ab altres companyons seus a la pilota» (Lieja 2004: vol. II, 244). Para no perder su anillo, lo coloca en la mano de «una ýdola de aram que stava allí prop». Ya nunca podrá recuperarlo. Al volver a su casa y acostarse con su mujer, la pareja «sentí entre ells una spessura, axí com si fos neula o broma, mas no qu·ell o pogués veure» (Lieja 2004: vol. II, 245). La bruma les impide mantener relaciones y, para subrayar la extrañeza del caso, el autor, ominisciente, se apresura a advertir al lector de que «abans de allò, ell era molt apte e covinent en aquel fet». En nuestra época, semejante comentario resulta chistoso. Es bastante probable que también lo fuera para el hombre del Medievo.

El joven escucha a continuación una voz que le recuerda que se ha desposado con Venus. La vida se convierte entonces en un «turment» hasta que decide buscar consejo en «Palamo, qui sabia de l'art de nigromància». El milagro que se obra en las versiones cristianizadas se trasforma en este exemple de origen pagano en magia negra. Palamo le entrega una carta para que se la lleve a unos demonios en una encrucijada de caminos. Allí, el joven protagonista se convierte en espectador silencioso de un estremecedor desfile, una especie de triunfo infernal, en el que destaca la figura de «una fembre vestida de vestedures de fembre de bordell, e aquelles vestedures eren ten primes que li parien les carns e feÿa los gests e los continents desonests». La caracterización de la «ýdola Venus» no puede separarse más de la imagen de la Virgen en los milagros marianos, en los que aparece representada apoteósicamente como una mujer hermosa e iluminada. Finalmente, la entrega de la carta de Palamo al diablo sirve para que el joven recupere el anillo $y$, con él, la potencia sexual y la felicidad conyugal.

La historia de Lieja sigue a Malmesbury y difiere bastante de la versión cristianizada de Beauvais, pero en esta y aquella se pueden rastrear rasgos comunes. En ambos casos se trata de un joven que juega a la pelota y que se desprende de un anillo colocándoselo a una estatua; el anillo viene a sellar en ambos casos el compromiso entre el mortal y la imagen. Esta se aparece por la noche en el tála- 
mo del protagonista y le exige que mantenga su compromiso. Como señalaba Asensio (1985), los elementos fundamentales, es decir, estatua, anillo y promesa están en ambos relatos. Sin embargo, entre una y otra historia, se ha producido un proceso de conversión: el relato pagano se ha cristianizado con la transposición de Venus a la Virgen. Ello lleva a subrayar la virtud de la castidad y a cambiar la felicidad mundana de la pareja, que puede consumar su unión al final de relato de Lieja, por la felicidad más auténtica y duradera, según la concepción cristiana, de la gloria celestial, que es el fin del protagonista en las versiones cristianizadas.

Esa transposición se aprovechó, de alguna forma, del proceso de humanización al que la Iglesia, tratando de canalizar un sentir popular, sometió a la Virgen, y ese proceso era lógico, aunque a veces parece rozar lo irreverente, si se tiene en cuenta la naturaleza humana de la María. Siguiendo caminos muy distintos, también la mitología grecolatina llegó a humanizar y antropomorfizar a sus dioses. Morawski y Wyrembek (1934: 25) dejan, sin embargo, muy claro que la humanización de la Virgen no tiene un origen pagano: «Cet anthropomorphisme malgré ses apparences payennes, n'est pas un trait de paganisme dans nos légendes; au contraire, c'est une curieuse spéculation populaire». No se opera la simple sustitución de Venus por la Virgen, sino posiblemente una analogía más compleja, como la de Eva-María. Sea como fuere, la conversión de Venus en la Virgen se ha revelado históricamente tan eficaz como la de otros muchos elementos paganos que fueron adoptados y reelaborados por el cristianismo.

\section{LAS VERSIONES HISPÁNICAS DEL MILAGRO DEL PROMETIDO DE LA VIRGEN}

La mayoría de las versiones hispánicas del milagro -y en especial, las que constituyen el eje central de este trabajo- suelen ser historias cristianizadas que tienen por protagonistas a la Virgen y a un clérigo (sea el localizado en Pisa o el hijo de un rey). Así sucede con el poema berceano XV de Milagros de Nuestra Señora y con el relato recogido por Fernando Baños en su edición de MdeNS, correspondiente con el manuscrito 110 de la Biblioteca Nacional de Madrid, que podría tener por fuente el mismo hipotético texto latino que la obra de Berceo. Compararemos el milagro berceano, titulado La boda y la Virgen, con el texto latino del ms. 110, encabezado de modo prolijo y descriptivo con el título: De clerico qui uxorem et omnia reliquit propter beatam Mariam. Escrito el de Berceo en verso castellano, es mucho más extenso que el ms. 110 y describe en detalle hechos, lugares y personajes, a través de las amplificaciones que las traducciones de la época acostumbraban a introducir.

Como en el manuscrito latino, Berceo abre su narración situando geográficamente los hechos en Pisa. Pero frente a la simple mención de la ciudad («In territorio civitatis que dicitur Pisa...») en el texto latino ${ }^{6}$, el poeta castellano amplía los datos al decir que es «cibdat bien cabdalera» (MdeNS, $330 \mathrm{~A})$ y que

${ }^{6}$ En esta y en otras menciones al manuscrito 110 de la Biblioteca Nacional de Madrid, me remito al texto ofrecido por Fernando Baños (Berceo 2011: 439) en su edición para la RAE. 
«en puerto de mar yaze, rica de grand manera» (MdeNS, $330 \mathrm{~B})$. Son solo tres pinceladas, pero aportan, sin duda, más información que el texto latino y enriquecen la narración. El original tiende a la síntesis, a la narración esquemática y seca de los hechos, mientras que Berceo siempre amplifica, enriquece, colorea, sitúa..., aunque no se aparte de su fuente. Como señala Montoya (1991b: 129), «la trama de la acción se presenta en el milagro literario como real e histórica, hasta el punto de que se precisan los lugares geográficos y la sucesión cronológica de los hechos», a diferencia de lo que sucede en los exempla, en los que, según añade el propio Montoya, «se descuidan estas precisiones y se acude a sintagmas de temporalidad indefinida (un clérigo... leíase un libro...), se olvidan nombres de personas y de lugares, se trata en todo caso de presentar una conducta».

Berceo aprovecha la segunda estrofa para engarzar el relato en la colección, recordando que el milagro XV tiene por protagonista a un devoto de la Virgen, «como fizieron otros muchos que de suso contamos / que de Sancta María fueron sos capellanos» (MdeNS, 331 A y B). Como en este ejemplo, Berceo se apoya a lo largo de los MdeNS en elementos de transición que dan coherencia y cohesión a la que, en principio, podría ser considerada simple enumeración de milagros sin relación entre sí. El personaje de la narración de Berceo es, como en su fuente, un clérigo, canónigo de la iglesia de San Casiano ${ }^{7}$, pero la descripción que de él hace el riojano vuelve a tener más sabor. Del amor del clérigo de San Casiano por la Virgen dice que «ésti amóla mucho, más que muchos cristianos / e faziéli servicio de pies e de manos» (MdeNS, 331). El final de la estrofa tiene un gusto feudal, y la imaginación vuela para reconstruir esa ceremonia de homenaje medieval en la que el vasallo, rendido de rodillas, colocaba sus manos juntas entre las de su señor (inmixtio manum), en actitud orante, para jurarle fidelidad. Es la postura de quien reza, pero en época feudal la imagen debía tener otras connotaciones, incluidas las de amante cortés que es vasallo de su señora y se arrodilla ante ella con la veneración que se debe a una diosa.

Como en el texto latino, Berceo señala que el clérigo rezaba las horas a la Virgen, y lo subraya como un hecho excepcional, pues sitúa el relato en un tiempo en el que semejante culto a la Virgen no estaba extendido:

[...] servitium devota mente reddebat horasque diei, que tunc temporis a paucissimis dicebantur, in eius honorem sedule decantabat (Ms. 110 Biblioteca Nacional de Madrid).
Non avié essi tiempo uso la clerecía dezir ningunas oras a ti, Virgo María pero elli diziélas siempre e cada día, avié én la Gloriosa sabor e alegría (MdeNS, 332).

La devoción diaria aquilata el amor del canónico por la Madre de Dios, «sabor e alegría» (MdeNS, 332 D) del clérigo. Esta expresión se corresponde, según explica Montoya (1985: 463), con el antiguo provenzal trovadoresco «plazer e alegranza». Berceo se dirige a María en segunda persona («dezir nin-

7 Según Brian Dutton (1967-1981: vol. II, 122), algunos textos localizan este milagro en San Casiano de Pavía y no en San Casiano de Pisa. 
gunas oras a ti, Virgo María», MdeNS, 332 B), como si el verdadero destinatario de los relatos que escribe Berceo fuera la Gloriosa y, de alguna forma, recopilar historias que ensalzan a la Virgen es el servicio amoroso que Berceo dedica a su Señora. Se aprecia en todo ello la presencia de rasgos feudo-vasalláticos, corteses. Por otro lado, la expresión «non avié essi tiempo» (MdeNS, $332 \mathrm{~A})$ recuerda el lenguaje popular de los cuentos folclóricos, en los que todo sucede en un tiempo pasado, lejano: «en aquel tiempo», «hubo un tiempo, «había una vez»... Encontramos aquí otra razón para definir, con Juan Manuel Rozas, el género miraculístico como pariente del cuento.

Tras la pintura espiritual del joven, el mundo entra en el relato. En el texto latino y en el milagro de Berceo, se habla de la riqueza de sus padres, lo que convierte al protagonista en «buen eredero» (MdeNS, $333 \mathrm{~B})$, capaz de un «buen casamiento, assaz cobdiziadero» (MdeNS, $333 \mathrm{D})$. No se extiende, sin embargo, el texto latino en semejantes pormenores, pues pasa a describir la situación que se produce tras la muerte de los padres del joven, «qui valde nobiles et divites fuerant». Amigos y parientes le aconsejan que tome, entonces, mujer y tenga hijos. El joven acepta en ambas versiones, pero lo que en el texto latino es un simple consejo acogido por el protagonista, en el milagro de Berceo se plantea como resultado de la contraposición espíritu-materia, entre la entrega a la Virgen y la aceptación de la norma social. La expresión de Berceo «movió.1 la ley del sieglo» evidencia el triunfo del mundo, razón por la que los remordimientos persiguen al protagonista.

Con las amplificaciones acostumbradas en la versión de Berceo, el momento culminante del milagro se desarrolla de forma similar en ambos relatos. El día que se celebra la boda, el novio se pone en camino con su cortejo, que se detiene ante una iglesia, pues el joven, acordándose de su amor y servicio a la Virgen, decide entrar en ella para orar. Allí, la aparición de la Madre de Dios al protagonista, al que la Virgen reprocha su abandono como lo haría cualquier novia, son el momento culminante de la historia milagrosa. Después tienen lugar, según se menciona en ambos relatos, la ceremonia y la fiesta posterior -que se describe prolijamente en el milagro de Berceo, mientras en el texto latino se señala de modo escueto: «Itaque ex more nuptias celebraverunt cum grandi leticia»-, pero de noche, «ante que entre sí ningún solaz oviessen», como recuerda el poeta riojano, el recién casado desaparece.

\begin{tabular}{|l|l|}
\hline $\begin{array}{l}\text { Nocte vero sequenti ingressus cubiculum } \\
\text { quasi cum uxore pausaturus, ignorantibus } \\
\text { cunctis clam domum egressus, tam } \\
\text { uxorem quam omnia que habere potuit } \\
\text { reliquit et, ut creditur, locum Dei servitio } \\
\text { et sancte Genitricis eius aptum querens, } \\
\text { quo habierit vel quo fine dicesserit } \\
\text { actenus sciri non potuit (Ms. 110). }\end{array}$ & $\begin{array}{l}\text { yoguiessen / ante que entre sí ningún } \\
\text { solaz oviessen / los brazos de la novia } \\
\text { non tenién qué prisiessen. / Issióseli de } \\
\text { manos, fússoli el marido, / nunca saber } \\
\text { podieron omnes dó fo caído; / sópolo la }\end{array}$ \\
$\begin{array}{l}\text { Gloriosa tener bien escondido, / no lo } \\
\text { consintió ella que fuesse corrompido } \\
(M d e N S, 347-348) .\end{array}$ \\
\hline
\end{tabular}

En el milagro latino, se da a entender que el joven sale a escondidas de la casa y abandona todo para dedicar su vida a Dios y a su Madre. En Berceo, el 
desenlace adquiere un carácter mágico-milagroso, según señala Montoya, quien, por su parte, ha comparado el milagro XV con el ejemplo CCII del Libro de los enxemplos de Clemente Sánchez de Vercial. Tras subrayar algunas diferencias evidentes, como la mayor extensión del relato de Berceo y su uso de la amplificatio frente a la abbreviatio del enxemplo CCII, o la existencia de referencias geográficas y otros datos informativos en el milagro frente a la indefinición del exemplum, Montoya señala que ambos coinciden en el relato del momento culminante del milagro:

Yendo á facer bodas este mancebo, falló en el camino una iglesia, é acordándose del servicio de la Virgen, entró en ella é comenzó decirlas horas de Sancta María, é aparecióle la Virgen á manera de sañuda é díjole: «iOh loco é sin fé! ¿por qué me dejaste á mí que soy tu amiga é esposa, porque quieres otra mas que á mí?» (Enxemplo CCII).
Yendo por la carrera a cumplir so depuerto / [...] halló una iglesia / [...] vínoli la Gloriosa, plena de bendición; / com qui sañosamientre díssoli tal razón: / «Don fol malastrugado, torpe e enloquido / [...] Assaz eras varón bien casado comigo, / yo mucho te quería como a buen amigo / mas tú andas buscando mejor de pan de trigo (MdeNS, 337-341).

Ambos relatos siguen en esta parte la misma hipotética fuente o quizá la obra de Sánchez de Vercial derive de los MdeNS, según cree Montoya (1991b: 131), pues en el Libro de los Enxemplos se alude al Livro de los Miraglos de la Virgen Maria. Llegamos así al desenlace, que presenta en ambos relatos grandes diferencias. Montoya las sitúa en los sujetos de las acciones narradas y en lo que él define como «tiempo real filosófico» $\mathrm{y}$ «tiempo teológico». Como se puede comprobar en el exemplo CCII, en prosa y abreviado, el sujeto de las acciones es el clérigo: «É él fué muy arrepentido [...] á la media noche, olvidando todo cuanto tenia, é dejado, fuyó é fuese, é entró en un monesterio de religiosos onde toda su vida servió á la Virgen Sancta Maria devotamente». Sería el mismo caso del manuscrito 110 de Madrid. Para Montoya (1991b: 132), el autor del Libro de los Enxemplos «trata de subrayar una conducta humana ejemplar para cuantos se encuentren en situación semejante», y añade que «la acción se desarrolla durante ese tiempo histórico, filosófico o ético». ${ }^{8}$

Sin embargo, en el milagro de Berceo, es María la que toma la iniciativa. Se aprecia en esta imagen marinera: «más echó la redmanga por y sancta María / e fizo en sequero una gran pesqería» (MdeNS, $346 \mathrm{C}$ y D). El protagonista, tras la aparición, sale de la iglesia -dice Berceo- «maestrado» (MdeNS, 343A). No se trata de la decisión personal del clérigo, sino que es resultado de una acción sobrenatural, una gracia. Montoya (1991b: 133) habla de unos «efectos casi mágicos», el elemento maravilloso cristiano, cuando llega la noche: «ante qe entre si ningun solaz oviessen, / los brazos de la novia non tenién qé prisiessen»

8 Explica Montoya (1991: 126): «Esta prolongación de la norma de conducta, o más bien esta virtualidad de proyección que adquiere el relato concebido bajo esta temporalidad hecha de historia y de ética, es el que podemos denominar tiempo histórico-filosófico. Solo adquiere plenitud de sentido en el ámbito de una determinada filosofía y su proyección será válida en tanto en cuanto perdure esta filosofía». 
(MdeNS, 347 C y D). El marido se ha esfumado o, más bien, la Virgen se lo ha arrebatado a su esposa: «sópolo la Gloriosa tener bien escondido, / no lo consintió Ella qe fuesse corrompido» (MdeNS, $348 \mathrm{C}$ y D). María es la verdadera protagonista del milagro, y su acción forma parte del tiempo real e histórico. Montoya (1991b: 133) lo explica así: «El espacio real y el tiempo real acogen la acción de María. El tiempo teológico es aquel que narra una acción sobrenatural como real e histórica en razón de la aceptación mutua de autor y lector». En este tiempo teológico reside, para Montoya, la distinción entre el milagro literario y otros géneros: exemplo, lai o cuento.

Hemos repasado los elementos fundamentales del milagro XV de Berceo, pero creemos necesario explicar algunos más, como el papel del «mundo», de los parientes y amigos que convencen al protagonista de aceptar la herencia y casarse contra su vocación. Cuando, el día de su boda, encuentra una iglesia en el camino y decide entrar a rezar, el novio «dessó las otras yentes fuera del portegado» (MdeNS, 338C) y, al salir, «todos avién querella, que avié detardado». Es descriptivo de lo que siente el protagonista, que quiere alejarse del mundo y estar con la Virgen, y de la oposición de este a su vocación. En otras versiones, el novio será mucho más tajante y expulsa a todos, incluida su prometida, de la iglesia, como en el milagro 657 de la colección de Jean Gobi y el VII.14.1 del Liber Mariae de Gil de Zamora.

No es necesario detenerse mucho más en la caracterización de la Virgen (humanizada, feminizada) y del clérigo como una pareja de amantes que se sirven de los tópicos del amor cortés («tan bien enna Gloriosa non podié entender», MdeNS, 336C). Similares elementos están en la mayor parte de los relatos analizados, incluida la cantiga alfonsina CXXXII. Términos corteses como «Sennor», para referirse a la amada, o como «coyta», para manifestar dolor de amor, expresan claramente el tipo de amor que une a los dos protagonistas de la cantiga, que arranca, como es habitual, con un refrán («Quen leixar Santa Maria / por outra, fará folia»). Este resume el milagro, subraya su principal contenido didáctico y apunta al momento culminante del relato, cuando la Virgen se aparece al novio y le recrimina su abandono por una mortal. Tras el desarrollo del refrán en las dos siguientes estrofas, el rey Sabio pinta al protagonista. El genio creador de Alfonso $\mathrm{X}$ omite algunos datos que aparecen en otros milagros, como la relación del joven con la iglesia de San Casián, y desarrolla otros más pintorescos y personales: «a un crerigo gremoso / e ric' e de mui gran guysa; mais era tant' omildoso / que celiço por camisa / sempre acaron vestia» (CSM, 23-27).

Pese a narrar los mismos hechos que el milagro de Berceo, la cantiga nos aparece como una obra genuina y original. La reelaboración formal que cada autor hace del mismo tema ofrece pistas sobre su maestría como escritores. Alfonso X da muestra de ello al describir, en cuatro estrofas, los esfuerzos de los parientes del protagonista para convencerle de que ha de buscar esposa, o al ofrecer soluciones creíbles y originales como la del sueño (a la que ya nos hemos referido al hablar de la cantiga XLII), dentro del cual sucede la escena culminante del milagro. En ella, la Virgen, en el centro de un gran cortejo que desciende del cielo, es caracterizada a través de un lenguaje menos popular, más elevado que el de Berceo, cuyas imágenes están llenas de rusticidad: 
Non es tu o que dizias / que mi mais que al amavas / e que me noytes e días / mui de grado saudabas? / Porqué outra fillar yas / amiga e desdennavas / a mi, que amor ti avia? (CSM, 101-116).
Assaz eras varón bien casado comigo, / yo mucho te quería como buen amigo, mas tú andas buscando mejor de pan de trigo; / non valdrás más por esso cuanto vale un figo (MdeNS, 341).

Las palabras de María provocan la desazón del clérigo, en cuyo corazón se fija la tópica «espinna» del sentimiento que duele, otro hallazgo expresivo del rey Sabio para referirse al amor místico. Llega el arrepentimiento, y el protagonista no puede comer, pese a que «as mesas mandou agynna / põer» (CSM, 122-123). En Berceo y, más aún en Alfonso X, se va viendo una cierta reacción emocional en los beneficiarios del milagro, que no se aprecia generalmente en otras versiones, lo que prueba la mayor profundidad de los personajes y la calidad literaria de estos autores.

E el no coraçon fito / lle ficou end'a espinna. / E, per com'achei escrito, / as mesas mandou agynna / põer; mais pouc'el comia (CSM, 119-123).
Sopo bien encobrirse el de suso varón la lengua poridat tovo al corazón: ridié e deportava, todo bien por razón, mas aviélo turrado mucho la vissión. (MdeNS, 345).

La escena de la noche de bodas también tiene en la cantiga CXXXII un carácter menos estereotipado que en el resto de los relatos, incluido el de Berceo, pues los novios se acercan, se miran, se abrazan, antes de que el protagonista deje el lecho, como si el recuerdo de la Otra no le permitiera ir más lejos. Es, según el autor, la Virgen quien «lle fez que o non fezesse», pero así narrado, resulta más verosímil que la misteriosa desaparición del novio en Berceo. Sucede por mediación de la Virgen, pero se da más autonomía al sujeto, que vence la tentación de la carne.

Por último, el relato anónimo de la colección leridana Miracles de la verge Maria presenta un matiz distinto con respecto a las otras dos versiones hispanas: en esta ocasión, el clérigo es «fiyl d'un rey e regina» (Miracles a: 45) y tiene un hermano que «devia ésser rey», según se repite a lo largo del texto, pero que muere, por lo que los súbditos piden al clérigo que ocupe el lugar de su hermano y se case. El día de su boda, se acuerda de la Virgen y comienza a rezar la antífona «es amica mea», lo que provoca la aparición de la Señora, «ab gran claredat», acompañada de ángeles y vírgenes. La Madre de Dios le llama «girmà» (Miracles a: 46), pero el breve monólogo de la Virgen adquiere después un tono cortés. La Reina del Cielo se muestra femenina y coqueta: «Pus dius que tam bela só, ¿per què·m cambies per altra?». La versión leridana es magra, a veces formularia, por lo que, después de oír la voz de la Virgen, sencillamente el clérigo se niega a casarse y «visqué en castedat, loan Déu e la verge santa Maria». No habrá, a diferencia de los relatos precedentes, noche de bodas. El protagonista se conduce como un autómata, no parece humano. A diferencia de las dos versiones anteriores, la abbreviatio domina la narración de los simples hechos; no hay profundidad alguna. La fuente del manuscrito leridano está, como se aprecia, muy alejada de la de Berceo y de Alfonso X. 
La versión más próxima al relato leridano parece ser, según apunta Bohigas (Miracles a: 14), la de Gil de Zamora, recogida por Fidel Fita (1888: 190-191), o una hipotética fuente de este último, aunque la narración leridana es mucho más esquemática. Al menos, en la versión del Liber Mariae, sabemos que el clérigo es hijo de Henricus, rey de Hungría. Existe también, por tanto, una referencia geográfica, que falta en la versión leridana. El rey del relato de Gil de Zamora tenía dos hijos, uno destinado a ser rey, que muere prematuramente, y otro dedicado al estudio y ordenado diácono, que consagra su virginidad a la Madre de Dios por haberle curado de una enfermedad grave. Este es un dato que solo aparece, de todas las versiones manejadas para este trabajo, en el milagro 657 de la colección de Jean Gobi. En este relato se añade que, después de haber hecho ese voto, «statim vidit cameram luce repletam et se curantum omnino repperit atque sanum» (Gobi 1991: 444). Un milagro dentro de otro milagro.

Pero volvamos al relato de Gil de Zamora editado por Fita. Muerto el hermano del protagonista, los barones del lugar le obligan a aceptar la corona y a casarse. Como en el relato leridano, el día de su boda el clérigo recita la antífona de la Hora Nona «Pulchra es et decora», procedente del Cantar de los Cantares. La Virgen se le aparece y se desarrolla un delicado diálogo místico entre la Madre de Dios -esposa hermosa del Cantar de los Cantares, Sennor del devoto trovador-, y el clérigo, apesadumbrado y perdido. Sin embargo, la versión leridana es aquí escueta:

\begin{tabular}{|l|l|}
$\begin{array}{l}\text { Si ego, inquit, pulchra sum, [ut] tu } \\
\text { asseris, et decora, quid est quod amorem } \\
\text { meum despicis, et amore carnali alteri } \\
\text { copularis? Numquid non ego pulchrior }\end{array}$ & $\begin{array}{l}\text { Oh, girmà! Pus dius que tam bela só, ¿per } \\
\text { què-m cambies per altra? (Miracles a: } \\
\text { sum quam illa? Ubi vidisti aliam }\end{array}$ \\
pulchriorem? Recordare quod tuam mihi \\
castimoniam devovisti, et quod abstinere \\
a concupiscentie incendiis promisisti, \\
cum te ab ingenti egritudine liberavi. \\
$\begin{array}{l}\text { Scias acatem quod, quia carni assensisti, } \\
\text { tantum distas a filio meo, quantum distat } \\
\text { celum a terra». Cui cum regis filius } \\
\text { respondisset: «Quid, o domina, vis ut } \\
\text { faciam? (Liber Mariae, VII, 60). }\end{array}$ \\
\hline
\end{tabular}

En la versión de Gil de Zamora, la Virgen propone al hijo del rey Henricus que renuncie a su esposa y a las tentaciones carnales y que se refugie en Aquileya, donde durante siete años lleva una vida eremítica, hasta ser elegido patriarca de la ciudad e instituir la fiesta a la Inmaculada Concepción. Este dato no consta en la versión leridana, sino solo en el ya indicado milagro de Jean Gobi (1991: 444), aunque en una narración mucho más condensada en la que la Virgen se aparece «splendida» y asistida por dos ángeles. La Madre de Dios se sirve de las mismas palabras del Cantar de los cantares para recriminarle su abandono y le recuerda que, si abraza las vanidades del mundo, «me in sponsam habere non poteris». Semejante advertencia sirve para que el protagonista de este relato, que Gobi dice haber leído en el Libe- 
llo de Miraculis beate Virginis ${ }^{9}$ (manuscrito Thott de Copenhague), huya en secreto y se haga eremita en Aquileya, tal y como se narra también en el milagro de Gil de Zamora. Todo ello podría indicar que ambas versiones tienen una fuente común o que, al menos, la de Jean Gobi deriva de la del franciscano español.

El esqueleto de esta historia aparece, con variantes, en la versión denominada por Pere Bohigas XIIA (Miracles a: 104-105) e incluida en el manuscrito 6 de l'Arxiu Capitular de la catedral de Barcelona. La diferencia más importante es que el protagonista no es hijo de rey, sino de caballero, y que no es clérigo, aunque sí reza las horas a la Virgen y ha hecho voto de castidad. Con todas estas diferencias, puede incluirse también en el grupo de los milagros del clérigo. Como en el relato leridano, la luz es, en esta versión, la característica de la Virgen, que aparece «molt clare e molt resplandent», se dirige al joven llamándolo «fill» y le pregunta: «¿vols ésser tu mon spòs?» (Miracles a: 105). La Virgen espera la respuesta libre del joven: «Oh, senyora! Ara pogués ésser jo vostron servidor. Terníats spòs». Es el devoto de la Virgen que habla el lenguaje del amor cortés a lo divino. La Madre de Dios le pide entonces que se retire a una ermita y le promete el paraíso. La decisión del joven obtiene la recompensa prometida, como se recuerda también en los relatos de Berceo y Alfonso X. Añade esta versión un apunte muy original sobre la reacción de familiares y amigos al enterarse de la huida secreta del novio: «E lo pare, e mare e amichs del novi romangueren molt trists quan lo novi havia axí jaquides les noces; mes, aprés alguns diez, ells, sabent lo fet, foren molt aconsolats e alegres». Y solo una nota más sobre las relaciones del miraculístico con otros géneros: el relato arranca con la expresión «esdevench-sa», con sabor a cuento popular.

El relato XIIB del manuscrito de la catedral de Barcelona es más fiel a la historia del clérigo de Pisa, aunque también más esquemático que las versiones antes mencionadas. Como en los relatos XII y XIIA de la edición de Bohigas, en el relato XIIB no llegan a celebrarse las bodas, la escena de la noche se suprime, y el joven renuncia a todo para huir secretamente, vivir en un lejano lugar «en serví de Déu e de la verge Maria» y morir «fort sanctament» (Miracles $a$ : 106).

\section{CONCLUSIONES}

Aunque estas y otras colecciones de milagros contribuyeron a difundir casi inalterados un puñado de relatos que habían seducido a devotos de toda Europa, Alfonso X y Berceo pueden ser considerados como auctores, en el sentido reclamado por san Buenaventura ${ }^{10}$, pues pusieron los primeros jalones en un

9 El manuscrito Thott de la Biblioteca Real de Copenhague es un códice, probablemente de la segunda mitad del siglo XIII, que recopila 53 milagros marianos tomados de compilaciones como las de Malmesbury, Cäsarius von Heisterbach y Hugo Farsito.

${ }_{10}$ Elisa Borsari (2010: 458) reproduce a san Buenaventura (1882: 14-15): «Quadruplex est modus faciendi librum. Aliquis enim scribit aliena, nihil addendo vel mutando; et iste mere dicitur scriptor. Aliquis scribit aliena, addendo, sed non de suo; et iste compilator dicitur. Aliquis scribit et aliena et sua, sed aliena tamquam principalia, et sua tamquam annexa ad evidentiam; et iste di- 
camino que condujo a la consagración de la creatividad como valor literario inexcusable desde el siglo XIX. La creatividad no es el rasgo que define a estos autores medievales, por supuesto, pero la historia de la literatura se ha encaminado hacia ese valor, el de la creatividad, porque ellos iniciaron la indagación de nuevos modos de contar historias tradicionales. Además de convertir la esquemática prosa latina en verso vernáculo, amplificaron los originales de un modo tan rico y muchas veces con tanto valor literario que fueron más allá de su papel de meros traductores. Han sido sus aportaciones tan fructíferas para la lírica castellana y la galaico-portuguesa que merecen abrir, como lo hacen, todas las historias de las literaturas ibéricas.

Para quienes, como el anónimo escritor leridano del códice publicado por Pere Bohigas, no merecen el distintivo de «auctores», aún tienen el valor de haber reflejado algunos de los fenómenos que caracterizaron el Occidente medieval. Sus milagros son, como los de Berceo y Alfonso X, reflejo de la exaltación de la devoción mariana que vivió la cristiandad en los siglos XII-XIII y que hizo de la Madre de Dios, en virtud de su humanidad y de su maternidad divina, una figura cercana y auxiliadora del hombre que lloraba en este valle de lágrimas. Son también la evidencia del triunfo de las lenguas vernáculas, que movió a los escritores a abandonar el latín para comunicarse con su público, pese a que muchos de ellos, de formación eclesiástica o relacionados con ambientes cortesanos, podrían haber escrito más cómodamente en la lengua de Cicerón.

Sus obras son asimismo la traslación a lo divino de una moda social y literaria del momento, el amor cortés. Autores como Coinci, Alfonso X o Gonzalo de Berceo se hicieron trovadores de la Señora celestial como el pobre Francisco aspiraba a ser el juglar de Dios. Wyrembek y Morawski (1934: 30) decían: «Troubadours profanes et trouveurs hagiografiques se rencontraient ainsi sur un même niveau supraterrestre: ceux-là en faisant de leurs dames des demi-déesses, ceux-çi en faisant de la Reine des cieux leur dame, leur amie». Los servidores de damas terrenales y los amantes de la reina celestial acabaron por confluir en el mundo de la literatura.

Por otra parte, las versiones hispánicas que hemos analizado han puesto de manifiesto la mayor fortuna y extensión que conoció en nuestra literatura el milagro del clérigo, el relato al que Poncelet adjudicó los códigos 866 (clérigo de Pisa) y 964 (clérigo hijo de rey). Las versiones del anillo, sin embargo, son mucho menos numerosas (cantiga XLII y eximpli 650 de la traducción catalana de la compilación Arnau de Lieja), como hemos visto, en la Península Ibérica.

Pero en definitiva, los escritores de todos estos relatos absorbieron las tendencias de la sociedad de su tiempo y las legaron a la posteridad. Además, tomaron elementos de la Antigüedad grecolatina para hacer evolucionar un relato germinal y hacerlo llegar hasta nuestros días incorporando las aportaciones de siglos de historia. Este trabajo concluye siendo un recordatorio de esa tarea y un agradecimiento a estos primeros auctores.

citur commentator non auctor. Aliquis scribit et sua et aliena, sed sua tamquam principalia, aliena tamquam annexa ad confirmationem; et talis debet dici auctor». 


\section{BIBLIOGRAFÍA}

Abreviaturas:

MdeNS: Berceo, G. de (2011) Milagros de Nuestra Señora.

CSM o Cantigas: Alfonso X (1986) Cantigas de Santa María.

Miracles a: Anónimo (1956) Miracles de la verge Maria.

Miracles b: Anónimo (1976) Miracles de la verge Maria.

Alfonso X (1988) Cantigas de Santa María, ed. de Jesús Montoya, Madrid, Ediciones Cátedra, Letras Hispánicas.

Alfonso X (1986) Cantigas de Santa María, ed. de Walter Mettman, Madrid, Clásicos Castalia, 3 vols.

Alfonso X (1985) Cantigas de Santa María, ed. de José Filgueira Valverde, Madrid, Ediciones Castalia.

Alfonso X (1945) Setenario, ed. y estudio introductorio de Kenneth H. Vanderford, Buenos Aires, Instituto de Filología de la Universidad de Filosofías y Letras.

Anónimo (1956) Miracles de la verge María. Collecció del segle XIV, ed. y estudio introductorio de Pere Bohigas, Barcelona, Muntaner.

Anónimo (1976) Miracles de la verge Maria. Un 'Mariale' lleidatà, ed. de Antoni M. ${ }^{a}$ Parramon, Lleida, Instituto de Estudios Ilerdenses.

Aragüés, J. (2014) «Ramón Llull: la invención del milagro mariano», Ruiz Arzalluz, I. et alii (eds.), Estudios de Filología e Historia en honor del profesor Vitalino Valcárcel, vol. I, Vitoria-Gasteiz, Universidad del País Vasco, pp. 91-109.

Aragüés, J. + Lacarra, M. J. + Domingo, T. (1993) Miracula Beatae Mariae Virginis: Colección latina medieval de milagros marianos en un Codex Pilarensis de la Biblioteca Capitular de Zaragoza, Zaragoza, Delegación Diocesana de Catequesis de Zaragoza y Parroquia San Pío X.

Asensio, J. (1985) «La cantiga XLII de Alfonso X y la Vénus d'Ille de Mérimée: polarizaciones de un tema. Homenaje a Alfonso X el Sabio (12841982)», Revista Canadiense de Estudios Hispánicos, vol. 9, n. ${ }^{\circ} 3$, pp. 451463.

Ayerbe-Chaux, R. (1975) El conde Lucanor. Materia tradicional y originalidad creadora, Madrid, José Porrúa Turanzas.

Baquero Goyanes, M. (1967) «El hombre y la estatua», Cuadernos hispanoamericanos, n. $^{\circ} 212-213$, pp. 506-518. 
Baum, P. F. (1919) «The Young Man Betrothed to a Statue», PMLA, 34 (4), pp. 523-579.

Berceo, G. de (2011) Milagros de Nuestra Señora, ed. de Fernando Baños, Barcelona, Real Academia de la Lengua y Galaxia Gutenberg.

Berceo, G. de (2008) Milagros de Nuestra Señora, ed. de Michael Gerli, Madrid, Cátedra.

Berceo, G. de (1997) Milagros de Nuestra Señora, ed. de Fernando Baños y estudio preliminar de Isabel Uría, Barcelona, Crítica.

Berceo, G. de (1990) Vida de Santo Domingo de Silos, ed. de Teresa Labarta de Chaves, Madrid, Clásicos Castalia.

Berceo, G. de (1986a) El libro de los Milagros de Nuestra Señora, ed. y estudio introductorio de Jesús Montoya, Granada, Universidad de Granada.

Berceo, G. de (1986b) Milagros de Nuestra Señora, ed. de Juan Manuel Rozas, Barcelona, Plaza y Janés.

Berceo, G. de (1967-1981) Obras completas (5 vols.), ed. de Brian Dutton, Londres, Támesis.

Bernardo de Claraval (1986) Obras completas IV. Sermones litúrgicos, Madrid, Biblioteca de Autores Cristianos.

Borsari, E. (2010) «Auctor y auctoritas: apuntes sobre la traducción de los clásicos durante la Edad Media», Fradejas, J. M. + Dietrick, D. A. et alii (eds.), Actas del XIII Congreso Internacional Asociación Hispánica de Literatura Medieval, Valladolid, Ayuntamiento de Valladolid y Universidad de Valladolid.

Bremond, C. + Le Goff, J. + Schmitt, J. C. (1982) «L'Exemplum», Typologie des sources du Moyen Age Occidental, 40, pp. 1-164.

Buenaventura (1882) «Proemii. Quaestio IV. Commentaria in quattuor libros sententiarum magistri Petri Lombardi», Opera Omnia, I, Firenze, Ad claras aquas (Quaracchi).

Cacho Blecua J. M. + Lacarra, M. J. et alii (coords.) (2003) Tipología de las formas narrativas breves románicas medievales (III), Granada y Zaragoza, Universidad de Granada y Universidad de Zaragoza.

Cacho Blecua, J. M. (1986) «Género y composición de los Milagros de Nuestra Señora de Gonzalo de Berceo», Homenaje a José María Lacarra, Pamplona, Gobierno de Navarra, Institución Ppe. de Viana, anejo 2, año 47, pp. 49-66.

Carrera, A. (1998) «Creencia y literatura en los Miracula beatae Mariae virginis», Cuadernos de Filología Clásica. Estudios latinos, n. ${ }^{\circ}$ 14, pp. 149-165.

Coinci, G. (1966) Les miracles de Nostre Dame, vol. I, ed. de Frédéric Kœnig, Genève, Librairie Droz. 
Deyermond, A. (1998) «Narrativas abiertas y narrativas cerradas en la poesía medieval castellana», Paredes, J. + Gracia, P. (coords.) Tipología de las formas narrativas breves románicas medievales, Granada, Universidad de Granada, pp. 21-53

Dronke, P. (1965) Medieval Latin and the Rise of European Love-Lyric, vol. I, Oxford, Clarendon Press.

Ferraresi, A. C. (1976), De amor y poesía en la España medieval. Prólogo a Juan Ruiz, México, El Colegio de México.

Fita, F. (1888) «Treinta leyendas por Gil de Zamora», Boletín de la Real Academia de la Historia, tomo 13, pp. 187-225.

Fita, F. (1885) «Cincuenta leyendas por Gil de Zamora combinadas con las Cantigas de Alfonso el Sabio», Boletín de la Real Academia de la Historia, tomo 7, pp. 55-144.

Gobi, J. (1991) La Scala Coeli, ed. de Marie-Anne Polo de Beaulieu, Paris, Centre National de la Reserche Scientifique.

Goldberg, H. (1998) Motif-Index of Medieval Spanish Folk Narratives, Arizona, Medieval \& Reinassance Text \& Studies. (En archive.org/stream/ motifindexofmedi00golduoft\#page/n5/mode/2up [consulta: 23 de enero de 2014]).

Gómez Redondo, F. (1998) «Narradores y oyentes en la literatura ejemplar», Paredes, J. + Gracia, P. (coords.), Tipología de las formas narrativas breves románicas medievales, Granada, Universidad de Granada, pp. 253-310.

Hauf, A. (2015) «In te Domina speravi. Presència del Psalterium Majus B. M. Virginis en la Vita Christi d'Isabel de Villena», Massot, J. et alii, Estudis de Llengua i Literatura Catalanes, LXIX [=Miscel-lània Jordi Bruguera, 3], pp. 17-50.

Heisterbach, C. (1998) Diálogo de milagros, vol. I, ed. de Zacarías Prieto Hernández, Zamora, Ediciones Monte Casino.

Keller, J. E. (1987) Collectanea Hispanica: Folkore and Brief Narrative Studies, Delaware, Juan de la Cuesta.

Keller, J. E. (1978) Pious Brief Narrative in Medieval Castilian and Galician Verse. From Berceo to Alfonso X, Kentucky, Lexington.

Keller, J. E. (1959) «The Motif of the Statue Bride in the Cantigas of Alfonso the Learned», Studies in Philology, vol. 56, n. ${ }^{\circ} 3$, pp. 453-458.

Kinkade, R. P. (1971) «A New Latin Source for Berceo's Milagros: ms. 110 of Madrid's Biblioteca Nacional», Romance Philology, 25, pp. 188-192.

Lacarra, M. ${ }^{a}$ J. (ed.) (1999) Cuento y novela corta en España (volumen I). Edad Media, prólogo general de Maxime Chevalier, Barcelona, Crítica.

Lacarra, M. ${ }^{\mathrm{a}}$ J. (1986) «El códice 879 del Archivo de la Catedral de Zaragoza y los Milagros de Nuestra Señora de Gonzalo de Berceo», Homenaje a José 
María Lacarra, Pamplona, Gobierno de Navarra, Institución Príncipe de Viana, anejo 2, año 47, pp. 387-394.

Le Goff, J. + Schmitt, J. C. (eds.) (2003) Diccionario razonado del Occidente medieval, Madrid, Akal.

Le Goff, J. (1999) La civilización del Occidente medieval, Barcelona, Paidós.

Lieja, A. (2004) Recull d'exemples i miracles ordenat per alphabet, ed. de Josep-Antoni Ysern Lagarda, Barcelona, Editorial Barcino.

Mainer, J. C. (2010-2013) Historia de la literatura española (9 vols.), Barcelona, Crítica.

Malmesbury, William of (1840) Gesta regum anglorum atque Historia novella (vol. I), ed. de Thomas Duffus Hardy, Londres, Sumptibus Societatis.

Mérimée, P. (1999) La Vénus d'Ille, ed. de Dominique Schultess-Fleur y Claudine Zenou-Gristein, Paris, Hachette. (En http://www.inlibroveritas.net/lire/ oeuvre2592.html\#page_1 [consulta: 14 de marzo de 2014]).

Montoya Martínez, J. (1991a) O cancioneiro marial de Alfonso X, o Sabio, Santiago de Compostela, Servicio de Publicación da Universidade de Santiago.

Montoya Martínez, J. (1991b) «El tiempo y el espacio en el milagro literario», Narrativa breve medieval románica, Granada, Biblioteca Universitaria de Estudios Románicos, Colección Romania, pp. 121-138.

Montoya Martínez, J. (1988) «El ms. 110 de la Biblioteca Nacional de Madrid: ¿un texto más próximo a Berceo?», Beltrán, V. (ed.), Actas del I Congreso de la Asociación Hispánica de Literatura Medieval, Barcelona, PPU, pp. 445-451.

Montoya Martínez, J. (1985) «El servicio amoroso, criterio unificador de los Milagros de Nuestra Señora», Soria, A. + Paredes, J. et alii (eds.), Estudios románicos dedicados al profesor Andrés Soria Ortega: en el XXV aniversario de la Cátedra de Literaturas Románicas. Granada, Universidad de Granada. Departamento de Filología Románica, pp.459-469.

Montoya Martínez, J. (1981) Las colecciones de milagros de la Virgen en la Edad Media. El milagro literario, Granada, Universidad de Granada.

Mussafia, A. (1886-1898) Studien zu den mittelalterlichen Marienlegenden, Wein, F. Tempsky.

Paredes, J. (2004) Para una teoría del relato. Las formas narrativas breves, Madrid, Editorial Biblioteca Nueva.

Paredes, J. + Gracia, P. (coords.) et alii (1998) Tipología de las formas narrativas breves románicas medievales, Granada, Universidad de Granada.

Poncelet, A. (1902) «Index miraculorum Beatae Virginis Mariae quae saeculis VI-XV latine conscripta sunt», Analecta Bollandiana, 21, pp. 242-360. 
Rozas López, J. M. (1976) Los milagros de Berceo, como libro y como género, Cádiz, UNED.

Sánchez de Vercial, C. (1884) «Libro de los Enxemplos», Escritores en prosa anteriores al siglo $X V$, ed. de Pascual Gayangos, Madrid, M. de Rivadeneyra, pp. 443-542.

Tarayre, M. (1999) La Vierge et le miracle. Le Speculum historiale de Vincent de Beauvais, Paris, Honoré Champion.

Thompson, S. (1989) Motif-index of folk-literature: a classification of narrative elements in folktales, ballads, myths, fables (6 vols.), Indiana, Indiana University Press.

Tubach, F. C. (1981) Index exemplorum: a Handbook of Medieval Religious Tales. Helsinki, Suomalainen Tiedeakatemia.

Vauchez, A. (2001) La espiritualidad del Occidente medieval, Madrid, Ediciones Cátedra.

Warner, M. (1991) Tú sola entre las mujeres. El mito y el culto a la virgen María, Madrid, Taurus Humanidades.

Wyrembek, A. + Morawski, J. (1934) Les légendes du fiancé de la Vierge dans la literatura médiéval. Essai de synthèse suivi de plusieurs textes inédits en ver et en prose, Poznań, Poznańskie Towarzystwo Przyjaciół Nauk.

Bases de datos consultadas en la red: gahom.ehess.fr/index.php y ec.aciprensa. com

\section{ANEXOS}

Los cuadros comparativos que a continuación se despliegan sintetizan este trabajo. En ellos se cotejan elementos constitutivos de las distintas versiones del milagro del prometido de la Virgen, constantes y omisiones significativas. Se comparan en ellos la cantiga alfonsina CXXXII, el milagro XV de Berceo y el número XII del manuscrito leridano Miracles de la verge Maria, así como versiones que aparecen en otras colecciones coetáneas, como los milagros XII A y XII B del manuscrito 6 de l'Arxiu Capitular de la catedral de Barcelona; los milagros 646 y 657 de la Scala Coeli de Jean Gobi; el VII, 87 del Speculum historiale de Vincent de Beauvais; las leyendas XVI.5.9 y VII.14.1 del Liber Mariae de Gil de Zamora, y los textos 42, 407, 581 y 650 del Recull d'exemples i miracles ordenat per alfabet, es decir, todos aquellos textos que se han manejado para la elaboración de este trabajo. La meta ha sido siempre mostrar cuánto tienen en común y cuánto de propio y distintivo cada uno de estos relatos. Se incluye asimismo en estos anexos una columna de «Catalogación», con códigos numéricos asociados a los relatos por Frederic Tubach, Stith Thompson, Harriet Goldberg..., que nos permiten comprobar otros aspectos de las relaciones entre los distintos relatos estudiados en este artículo. 

ANEXO 1

\begin{tabular}{|c|c|c|c|c|c|c|c|c|c|c|c|}
\hline & Género & Catalogación & Refer. geográfica & $\begin{array}{c}\text { Beneficiario } \\
\text { milagro }\end{array}$ & Virgen & Mundo & Bodas & Magia milagrosa & $\begin{array}{l}\text { Conversión / } \\
\text { Premio }\end{array}$ & Rasgos corteses & $\begin{array}{l}\text { Elementos } \\
\text { distintivos }\end{array}$ \\
\hline $\begin{array}{l}\text { Milagros de Nuestra } \\
\text { Señora (XV), de } \\
\text { Berceo: "La boda y } \\
\text { la Virgen". }\end{array}$ & Verso castellano. & $\begin{array}{l}\text { Tubach: } 5148 \\
\text { (Virgin, Blessed, } \\
\text { statue of married, } \\
\text { variante A: Virgin } \\
\text { speaks to a devot } \\
\text { clerk) / Thompson: } \\
\text { T376.1 (Motif: Man } \\
\text { leaves earthly bride } \\
\text { for service of Virgin) } \\
\text { Poncelet: } 866\end{array}$ & $\begin{array}{l}\text { Enna villa de Pisa... } \\
\text { (v. 330). }\end{array}$ & \begin{tabular}{|l|} 
avié hí un calonge \\
de buena alcavera; // \\
dizién Sant Cassïán \\
ond el canonge era \\
(330) // ésti amóla \\
[Virgen] mucho, [...] \\
e faziéli servicio de \\
piedes y manos (331) \\
/ diziélas [horas] \\
sempre (332).
\end{tabular} & $\begin{array}{l}\text { plena de } \\
\text { bendición com } \\
\text { qui sañosamientre } \\
\text { díssoli... (339) // } \\
\text { echó la redmanga } \\
\text { por ý Sancta María } \\
\text { /e fizo [...] grand } \\
\text { pesquería (346) // } \\
\text { no lo consintió ella } \\
\text { [Virgen] que fuesse } \\
\text { corrompido (348). }\end{array}$ & $\begin{array}{l}\text { era buen eredero } \\
\text { [...] tenié buen } \\
\text { casamiento, assaz } \\
\text { cobdiziadero (333) // } \\
\text { [los parientes] diziénli } \\
\text { que fizizese algunos } \\
\text { engendrados (334) } \\
\text { // movió.'l la ley del } \\
\text { sieglo (335). }\end{array}$ & $\begin{array}{l}\text { Ovieron ricas bodas } \\
\text { e muy grand alegría } \\
\text { (34)6///Cuando veno } \\
\text { la noch, la ora que } \\
\text { dormiessen, fizieron } \\
\text { a los novios lecho en } \\
\text { que yoguiesen (347) }\end{array}$ & \begin{tabular}{l|} 
ante que entre \\
sí ningún solaz \\
oviessen, / los brazos \\
de la novia non tenién \\
qué prisiessen (347) \\
// Issióseli de manos, \\
fússoli el marido, [...] \\
sópolo la Gloriosa \\
tener bien escondido \\
(348).
\end{tabular} & $\begin{array}{l}\text { Asmando esta cosa } \\
\text { de corazón cambiado } \\
\text { (338) // Desso mugier } \\
\text { fermosa y muy grand } \\
\text { posesión (349) // sovo } \\
\text { escondido faciendo } \\
\text { oración, / por ond } \\
\text { ganó la alma de Dios } \\
\text { buen gualardón (350). }\end{array}$ & \begin{tabular}{|l} 
tan bien enna \\
Gloriosa non podié \\
entender (336)// \\
Assaz eras varón bien \\
casado comigo, yo \\
mucho te quería como \\
a buen amigo (341)/// \\
a mí non dessarás por \\
con otra tener $(342)$.
\end{tabular} & $\begin{array}{l}\text { ante que entre sí } \\
\text { ninguń solaz oviessen, } \\
\text { / los brazos de la } \\
\text { novia non tenién qué } \\
\text { prisiessen (elemento } \\
\text { humorístico-grotesco) } \\
\text { (347). }\end{array}$ \\
\hline $\begin{array}{l}\text { Cantigas de Santa } \\
\text { Marí (132), de } \\
\text { Alfonso X: “Esta é } \\
\text { como Santa Maria } \\
\text { fez ao crerigo que Ile } \\
\text { prometera castidade } \\
\text { e sse casara que } \\
\text { leixasse ssa moller e } \\
\text { a fosse servir”. }\end{array}$ & \begin{tabular}{|l|} 
Verso galaico- \\
portugués.
\end{tabular} & $\begin{array}{l}\text { Tubach: } 5148 \text { (Var. } \\
\text { A) Thompson: } \\
\text { T376.1 Poncelet: } 866\end{array}$ & $\begin{array}{l}\ldots \text { un maravilloso } \\
\text { Imiragr' avẽo en } \\
\text { Pisa... (21-22) }\end{array}$ & \begin{tabular}{|l|} 
un crerigo fremoso \\
/ e ric' e de muy \\
gran guysa; era \\
tan omildoso que \\
celiço por camisa \\
[... vestia" (23-27) \\
// demais las oras \\
rezava (29) // pola \\
virgìninidade / de la \\
sua guardaba (32-33).
\end{tabular} & $\begin{array}{l}\text { dormindo viu mui } \\
\text { gran gente / que do } \\
\text { ceo decendia, [...] E } \\
\text { a Virgen escolleyta / } \\
\text { tragia enno meogo / } \\
\text { da companna (90-95). }\end{array}$ & $\begin{array}{l}\text { seu padr' e sa madre } \\
\text { mortos / foron, e } \\
\text { enrrequecendo / foi } \\
\text { el (38-39) // tanto o } \\
\text { trouxeron / per faagu' } \\
\text { e per engano / que } \\
\text { outorgag-lle feqeeron } \\
\text { / que casass'en aquel } \\
\text { ano (53-56). }\end{array}$ & $\begin{array}{l}\text {... e des que soos } \\
\text { ficaron / e el viu dela } \\
\text { o peyto, logo ambos } \\
\text { ss' abracaron (133- } \\
137) / / \text { a Virgen de } \\
\text { piedade / lle fez que } \\
\text { o non fezesse. / E do } \\
\text { leit' enton s' ergia } \\
\text { (144-46). }\end{array}$ & & $\begin{array}{l}\text { as mesas mandou } \\
\text { agynna / põer; mais } \\
\text { pouc' el comia (122- } \\
123) \text { // fillou de mui } \\
\text { gran pobreza / por } \\
\text { servir a que senlleyra } \\
\text { / foi e será en nobreza } \\
\text { (151-154) // [el alma] } \\
\text { levou u Deus siia } \\
\text { (163). }\end{array}$ & \begin{tabular}{|l} 
da Sennor de piedade \\
(29) // dizias que mi \\
mais que al amavas \\
[.... Porque outra \\
fillar yas / amiga e \\
desdennavas / a mi, \\
que amor ti avia? \\
(101-107 // no \\
coraçon fito / lle ficou \\
end' a espinna (119- \\
120).
\end{tabular} & $\begin{array}{l}\text { dormindo viu mui } \\
\text { gran gente / que do } \\
\text { ceo decendia }(90-91) \text {. }\end{array}$ \\
\hline $\begin{array}{l}\text { Miracles de la } \\
\text { verge Maria (XII), } \\
\text { colección leridana: } \\
\text { "Un clergue, } \\
\text { enamorat de la } \\
\text { Verge, deixa la } \\
\text { muller que volien } \\
\text { donar-li i promet } \\
\text { viure en castedat". }\end{array}$ & Prosa catalana. & $\begin{array}{l}\text { Tubach: } 5148 \\
\text { Thompson: T376.1 } \\
\text { Poncelet: } 866\end{array}$ & & \begin{tabular}{|l|} 
Era un clergue, fiyl \\
d'un rey e regina, e \\
aquest clergue havia \\
un girmà qui devia \\
ésser rey // començà- \\
les a dir (las horas), \\
axí com ja havie \\
acustumat.
\end{tabular} & $\begin{array}{l}\text { la Verge santa } \\
\text { Maria, ab gran } \\
\text { claredat, devalà } \\
\text { bé acompanyada } \\
\text { d'àngels e de verges. }\end{array}$ & $\begin{array}{l}\text { axí anaren-se'n al } \\
\text { clergue los hòmens de } \\
\text { la terra, e pregaren-lo } \\
\text { que, [...] li plagués } \\
\text { que volgués atorgar } \\
\text { que él fos rey // E les } \\
\text { gents esposaren-li } \\
\text { muyler. }\end{array}$ & & & $\begin{array}{l}\text { E lo clergue que oy } \\
\text { la veu de la verge } \\
\text { santa Mariaa, parti's } \\
\text { del regisme e no } \\
\text { volch penre muyler, } \\
\text { e visqué en castedat, } \\
\text { loan Déu e la verge } \\
\text { santa Maria. }\end{array}$ & $\begin{array}{l}\text { Pus dius que tam } \\
\text { bella só, iper què-m } \\
\text { cambies per altra? }\end{array}$ & $\begin{array}{l}\text { que devia ésser } \\
\text { rey (se repite } \\
\text { cinco veces, y esta } \\
\text { reiteración recuerda } \\
\text { estilísticamente a los } \\
\text { cuentos). }\end{array}$ \\
\hline $\begin{array}{l}\text { Miracles de la } \\
\text { verge Maria } \\
\text { (XIIA), manuscrito } \\
\text { de Barcelona: } \\
\text { "Esdevench-sa } \\
\text { que fou un fill de } \\
\text { cavaller, qui havia en } \\
\text { fort gran devoció la } \\
\text { Verge". }\end{array}$ & Prosa catalana. & $\begin{array}{l}\text { Tubach: } 5148 \\
\text { Thompson: T376.1 } \\
\text { Poncelet: } 866\end{array}$ & & $\begin{array}{l}\text { Esdevench-sa que } \\
\text { fou un fill de cavaller, } \\
\text { qui havia en fort } \\
\text { gran devocío la verge } \\
\text { Maria, en tant que } \\
\text { [...], tot jorn dehïa } \\
\text { les sues hores, e posà } \\
\text { en son cor de tenir } \\
\text { verginitat. }\end{array}$ & $\begin{array}{l}\text { la verge Maria li } \\
\text { aparegué molt clare e } \\
\text { molt resplandent. }\end{array}$ & $\begin{array}{l}\text { lo pare e la mare ab } \\
\text { lurs amichs feren } \\
\text { tant que lo fill atorgà } \\
\text { de pendra muller } \\
\text { // lo pare e la mare } \\
\text { impugnaren molt que } \\
\text { no ho fayés [horas], } \\
\text { fins al menys que } \\
\text { fossen dinats. }\end{array}$ & & & $\begin{array}{l}\text { E tantost lo novi } \\
\text { jaquí les noces, e } \\
\text { son pare e sa mare. } \\
\text { Amagadament parti's } \\
\text { de aquíe anà-se'n al } \\
\text { hermitatge, e visch } \\
\text { molt santament, e } \\
\text { après sa mort fou } \\
\text { collocloat en la glòria. }\end{array}$ & \begin{tabular}{|l|} 
"Oh, senyora! Ara \\
pogués ésser jo \\
vostron servidor. \\
Terníats sposs".
\end{tabular} & $\begin{array}{l}\text { lo pare e la mare } \\
\text { impugnaren molt } \\
\text { que no ho fayés } \\
\text { [horass], fins al menys } \\
\text { que fossen dinats // } \\
\text { [padres y amigos] } \\
\text { romangueren molt } \\
\text { trists quan lo novi } \\
\text { havia axí jaquides. }\end{array}$ \\
\hline $\begin{array}{l}\text { Miracles de la verge } \\
\text { Maria (XIIB), } \\
\text { manuscrito de } \\
\text { Barcelona: "En la } \\
\text { sgleya de sent Cassià } \\
\text { de la ciutat de Pisa, } \\
\text { havia un canonge } \\
\text { fort devot a la verge } \\
\text { Maria". }\end{array}$ & $\begin{array}{l}\text { Prosa catalana. } \\
\text {. }\end{array}$ & $\begin{array}{l}\text { Tubach: } 5148 \\
\text { Thompson: T376.1 } \\
\text { Poncelet: } 866\end{array}$ & $\begin{array}{l}\text { En la sgleya de sent } \\
\text { Cassià de la ciutat de } \\
\text { Pisa... }\end{array}$ & $\begin{array}{l}\text { havía un canonge } \\
\text { fort devot a la verge } \\
\text { Maria // lo dit olim } \\
\text { canonge deya tot } \\
\text { jorn a la gloriosa } \\
\text { verge Maria les hores } \\
\text { acustumades. }\end{array}$ & $\begin{array}{l}\text { la verja Maria li } \\
\text { aparech e dix-li } \\
\text { per qué lo dit olim } \\
\text { canonge amava } \\
\text { més aquella que li } \\
\text { parlaven per muler, } \\
\text { que no feya la Mare } \\
\text { de Déu. }\end{array}$ & $\begin{array}{l}\text { Aquest monjo havia } \\
\text { pare e mare fort richs, } \\
\text { los quals per temps } \\
\text { moriren, e [...] per } \\
\text { què los pares e amichs } \\
\text { del dit canonge } \\
\text { tractaren e feren tant } \\
\text { que.l tragueren del } \\
\text { monastir per dar-li } \\
\text { muller. }\end{array}$ & & & $\begin{array}{l}\text { no curant-sa de la } \\
\text { muller que li volien } \\
\text { dar ni de la riquesa } \\
\text { que son pare e } \\
\text { sa mare li havien } \\
\text { lexadess secretament } \\
\text { lexà̀u tot en banda, e } \\
\text { anà-se'n sacratament } \\
\text { en un loch luny en } \\
\text { serví de Déu e de la } \\
\text { verge. }\end{array}$ & \begin{tabular}{|l|} 
dix a la verge Maria \\
que no havia res al \\
món que ell tant amàs \\
com feya la gloriosa \\
verge Maria.
\end{tabular} & $\begin{array}{l}\text { dix a la verge Maria } \\
\text { que no havia res al } \\
\text { món que ell tant amàs } \\
\text { com feya la gloriosa } \\
\text { verge Maria. }\end{array}$ \\
\hline $\begin{array}{l}\text { Speculum historiale } \\
\text { (VII, 87), de } \\
\text { Vincent de Beauvais: } \\
\text { "De puero qui } \\
\text { Virginis imaginem } \\
\text { annulo subarrhavit". }\end{array}$ & Prosa latina. & $\begin{array}{l}\text { Tubach: } 5148 \\
\text { Thompson: T376 } \\
\text { Poncelet: } 1489\end{array}$ & $\begin{array}{l}\text {.. ante quandam } \\
\text { ecclesiam... (no se } \\
\text { dice cuál ni dónde). }\end{array}$ & $\begin{array}{l}\text { Quorum [pueri } \\
\text { clerici] unus qui } \\
\text { habebat in manu } \\
\text { annulum quem ei } \\
\text { puella quaedam } \\
\text { donauerat carnali } \\
\text { amore ducta... }\end{array}$ & $\begin{array}{l}\text { ante imaginem } \\
\text { Virginis Mariae, } \\
\text { intuitus eam et } \\
\text { admirans euis } \\
\text { pulchritudinem... }\end{array}$ & $\begin{array}{l}\text { Quod illi audientes } \\
\text { eum saeculo } \\
\text { renunciare et } \\
\text { uotum persoluere } \\
\text { hortabantur, quatenus } \\
\text { Dei genitricis seruus } \\
\text { et amicus sicut dixerat } \\
\text { haberetur. }\end{array}$ & $\begin{array}{l}\text { Beata Virgo Maria, } \\
\text { quiasi inter ipsum } \\
\text { et uxorem eius } \\
\text { media recumbens } \\
\text { apparuit, annulum } \\
\text { digito praetendens } \\
\text { et infideli-tatis eum } \\
\text { arguens. }\end{array}$ & \begin{tabular}{|l|} 
"amare et tibi seruire \\
decerno" [...] Sic \\
igitur praefatus puer \\
annulum suum digito \\
imaginis[...] mirabile \\
dictu, digitum suum \\
imago contrixit".
\end{tabular} & $\begin{array}{l}\text { relictis omnibus quae } \\
\text { habebat, eadem nocte } \\
\text { in eremum clam } \\
\text { secessit, [...] dominae } \\
\text { et amicae suae } \\
\text { cunctis diebus uitae } \\
\text { suae deuoto animo } \\
\text { deseruiuit. }\end{array}$ & \begin{tabular}{|l|} 
non sicut prius blande \\
alloquentem, sed \\
cum indignatione \\
uultum auertentem, \\
et tormenta durissima \\
pro contemptu \\
sui et uoto irrito \\
comminantem.
\end{tabular} & $\begin{array}{l}\text { En la noche de } \\
\text { bodas, la Virgen se le } \\
\text { aparece en un sueño, } \\
\text { y el joven cree que se } \\
\text { trata de un fantasma } \\
\text { (humor). El momento } \\
\text { álgido sucede antes en } \\
\text { otros textos. }\end{array}$ \\
\hline $\begin{array}{l}\text { Scala Coeli (646), } \\
\text { de Jean de Gobi: } \\
\text { "Legitur in Mariale } \\
\text { Magno quod quidam } \\
\text { juvenis a quadam } \\
\text { juvencula". }\end{array}$ & \begin{tabular}{|l} 
Prosa latina. \\
\end{tabular} & $\begin{array}{l}\text { Tubach: } 5148 \\
\text { Thompson: T376 } \\
\text { Poncelet: } 1489\end{array}$ & $\begin{array}{l}\ldots \text { ante portam } \\
\text { ecclesie... (no se dice } \\
\text { cuál ni dónde). }\end{array}$ & $\begin{array}{l}\text { quidam juvenis a } \\
\text { quadam juvencula, } \\
\text { que eum corrupte } \\
\text { amabat, annulum } \\
\text { recepit in signum } \\
\text { amoris... }\end{array}$ & $\begin{array}{l}\text { cum aspexisset } \\
\text { pulcritudinem } \\
\text { ymaginis beate } \\
\text { Virginis, ipsam } \\
\text { elegit in sponsam } \\
\text { et in signum hujus } \\
\text { annulum impressit in } \\
\text { digitum. }\end{array}$ & $\begin{array}{l}\text { Qui territus sociis } \\
\text { denunciavit et illi } \\
\text { movebant eum ad } \\
\text { religionis ingressum. } \\
\text { Sed atractus a } \\
\text { concupiscenciis } \\
\text { mundi... }\end{array}$ & $\begin{array}{l}\text { cum de nocte } \\
\text { ingressus fuisset } \\
\text { lectum, ymago sibi } \\
\text { apparuit annulum } \\
\text { demonstrans } \\
\text { arguendo } \\
\text { infidelitatem ejus. }\end{array}$ & $\begin{array}{l}\text { Tunc ymago manu } \\
\text { constricta cum annulo } \\
\text { signum consensus } \\
\text { monstravit. }\end{array}$ & $\begin{array}{l}\text { Subito evigilatus } \\
\text { surrexit de lecto, } \\
\text { et dimissis } \\
\text { vanitatibus mundi } \\
\text { et complacentiis in } \\
\text { heremo sue amatrici } \\
\text { servivit. }\end{array}$ & & $\begin{array}{l}\text { Legitur in Mariale } \\
\text { Magno... Se } \\
\text { introduce este relato } \\
\text { en un capítulo que } \\
\text { condena la lujuria y } \\
\text { exalta la pureza. }\end{array}$ \\
\hline
\end{tabular}


ANEXO 2

\begin{tabular}{|c|c|c|c|c|c|c|c|c|c|c|c|}
\hline & Género & Catalogación & Refer. geográfica & Beneficiario milagro & Virgen & Mundo & Bodas & Magia-milagrosa & Conversión / Premio & Rasgos corteses & $\begin{array}{l}\text { Elementos } \\
\text { distintivos }\end{array}$ \\
\hline $\begin{array}{l}\text { Scala Coeli (657), de } \\
\text { Gobi: "Legitur in } \\
\text { Libello de Miraculis } \\
\text { beate Virginis quod } \\
\text { fuit quidam clericus } \\
\text { filius regis Ungarie". }\end{array}$ & Prosa latina. & $\begin{array}{l}\text { Tubach: } 5148 \text { (Virgin, } \\
\text { statue of married) / } \\
\text { Thompson: T376.1 } \\
\text { (Man leaves earthly } \\
\text { bride for service of } \\
\text { Virgin) / Poncelet: } 964\end{array}$ & Ungarie. & $\begin{array}{l}\text { quidam clericus et } \\
\text { dyaconus filius regis } \\
\text { Ungarie, sic etiam } \\
\text { devotus ut antequam } \\
\text { comederet diceret } \\
\text { horas ejus. }\end{array}$ & $\begin{array}{l}\text { splendida Virgo } \\
\text { apparuit ei ante altare, } \\
\text { duobus assistentibus } \\
\text { angelis.... }\end{array}$ & $\begin{array}{l}\text { Tandem moritur pater } \\
\text { absque herede alio, } \\
\text { et ideo inducitur ab } \\
\text { amicis ne regnum } \\
\text { careret herede ut } \\
\text { contrahet. }\end{array}$ & & & $\begin{array}{l}\text { venit Aquileiam, } \\
\text { et super rupem } \\
\text { heremiticam duxit } \\
\text { vitam. Tandem } \\
\text { factus patriarcha } \\
\text { instituit fieri festum } \\
\text { Conceptionis. }\end{array}$ & $\begin{array}{l}\text { [dicit:] “Quam pulcra } \\
\text { est amica mea” [...] } \\
\text { "Si pulcra sum et } \\
\text { decora ut asseris, cur } \\
\text { me dimittis et aliam } \\
\text { capis?". }\end{array}$ & $\begin{array}{l}\text { voverat beate Virgini } \\
\text { quod si eum curaret } \\
\text { perpetuam castitatem } \\
\text { servaret.... II } \\
\text { instituit fieri festum } \\
\text { Conceptioni. }\end{array}$ \\
\hline $\begin{array}{l}\text { Recull d'exemples } \\
\text { imiracles ordenat } \\
\text { per alfabet (42), de } \\
\text { Arnau de Lieja: } \\
\text { "Miracle de santa } \\
\text { Agnès verge". }\end{array}$ & Prosa catalana. & $\begin{array}{l}\text { Tubach: } 5148 \\
\text { / Thompson: } \\
\text { T376 (Young man } \\
\text { betrothed to statue) / } \\
\text { Poncelet: --- }\end{array}$ & $\begin{array}{l}\text { la sgleya de Sante } \\
\text { Agnès ¿de dónde? }\end{array}$ & $\begin{array}{l}\text { un clergue }[\ldots] \\
\text { temptat de peccat de } \\
\text { luxúria, e no volent } \\
\text { ofendre nostre senyor } \\
\text { Déu... }\end{array}$ & & $\begin{array}{l}\text { un clergue de la } \\
\text { sgleya de Sante Agnès } \\
\text { ere molt greument } \\
\text { temptat de peccat de } \\
\text { luxúria... }\end{array}$ & & $\begin{array}{l}\text { la ymage alarguà la } \\
\text { mà etrasch l'anell del } \\
\text { dit clergue... }\end{array}$ & $\begin{array}{l}\text { la ymage [...] tirà- } \\
\text { li tentost aquella } \\
\text { temptació. }\end{array}$ & & $\begin{array}{l}\text { recompte en los } \\
\text { Miracles de sancte } \\
\text { Agnès... //E encara } \\
\text { vuy en dia la ymage } \\
\text { té lo dit anell en } \\
\text { lo dit. }\end{array}$ \\
\hline $\begin{array}{l}\text { Recull d'exemples } i \\
\text { miracles... (407), de } \\
\text { A. Lieja: "Miracle } \\
\text { con una ymatge } \\
\text { de lla verge Maria } \\
\text { parlà ab un scolà". }\end{array}$ & Prosa catalana. & $\begin{array}{l}\text { Tubach: } 5148 \\
\text { Thompson: T376.1 } \\
\text { Poncelet: } 866\end{array}$ & & $\begin{array}{l}\text { un scolà qui havie } \\
\text { singular devoció en } \\
\text { la verge Maria, deỹa } \\
\text { quescun die les hores } \\
\text { de lla dita Verge ab } \\
\text { gran devoció. }\end{array}$ & $\begin{array}{l}\text { quant ac acabat de } \\
\text { dir les dites ores, la } \\
\text { imatge de llat verge } \\
\text { Maria parlà. }\end{array}$ & $\begin{array}{l}\text { E morts son pare e } \\
\text { sa mare, eretà ell } \\
\text { tots lurs béns. E, per } \\
\text { consell de sos amichs, } \\
\text { sposà per muller una } \\
\text { fadrina... }\end{array}$ & $\begin{array}{l}\text { la nit de lles bodes, } \\
\text { ans que conegués sa } \\
\text { muller carnalment, } \\
\text { isqué's de case. }\end{array}$ & & $\begin{array}{l}\text { desemparà la muller } \\
\text { e tot quant havie e } \\
\text { mès-se en un ordre. E } \\
\text { visque e eacabà la sua } \\
\text { vida en servey de lla } \\
\text { dita gloriosa verge. }\end{array}$ & $\begin{array}{l}\text { lla verge parla et dix- } \\
\text { li aytals paraules: “O } \\
\text { escola folle en fell!! } \\
\text { Per què lexes a mi, } \\
\text { que son te esposa e } \\
\text { te amiga, per neguna } \\
\text { altre?". }\end{array}$ & $\begin{array}{l}\text { Segons que.s } \\
\text { recompte en los } \\
\text { Miracles de lla verge } \\
\text { Maria... }\end{array}$ \\
\hline $\begin{array}{l}\text { Recull d'exemples } \\
\text { i miracles ordenat } \\
\text { per alfabet (581), } \\
\text { de Arnau de Lieja: } \\
\text { "Miracle de lla } \\
\text { Verge, ue un scolà } \\
\text { qui se enemorà de } \\
\text { una ymatge de lla } \\
\text { dita Verge". }\end{array}$ & Prosa catalana. & $\begin{array}{l}\text { Tubach: } 5148 \\
\text { Thompson: T376 } \\
\text { Poncelet: } 1489\end{array}$ & $\begin{array}{l}\text { devant una esgleya } \\
\text { (no se dice cuál ni } \\
\text { dónde). }\end{array}$ & $\begin{array}{l}\text { E la un d'ells (jóvens } \\
\text { escolans) tenie } \\
\text { un anell en la mà } \\
\text { que li havie donat } \\
\text { una fadrina, sa } \\
\text { enemorada. }\end{array}$ & $\begin{array}{l}\text { aparech-li la dita } \\
\text { ymatge de santa } \\
\text { Maria monstrant-li en } \\
\text { lo dit l'anell. }\end{array}$ & & $\begin{array}{l}\text { stant en lo lit ab sa } \\
\text { sposa, aparech-li la } \\
\text { dita ymatge de santa } \\
\text { Maria monstran-li } \\
\text { en lo dit l'anell, } \\
\text { reprenent-lo perquè } \\
\text { no li ere stat leyal } \\
\text { [...] amenaçant-lo si } \\
\text { no tenie ço que a ella } \\
\text { havie promès. }\end{array}$ & $\begin{array}{l}\text { E, aquestes paraules } \\
\text { dites, meté-li lo dit } \\
\text { anell en lo dit de lla } \\
\text { dita ymatge e, tentost, } \\
\text { la ymatge strengué la } \\
\text { mà ab lo dit anell. }\end{array}$ & $\begin{array}{l}\text { lo dit scolà, aquella } \\
\text { nit, lexà ma mullere e } \\
\text { tots sos béns, e mès- } \\
\text { se hermità en l'erm e } \\
\text { serví tota la sua vida } \\
\text { santement a la verge } \\
\text { Maria. }\end{array}$ & \begin{tabular}{|l} 
dix a la imatge: \\
"Vertaderament est \\
tu pus bella que totes \\
les altres fembres, \\
e encare més que \\
aquella qui-m donà \\
aquest anelll E, per \\
tal, lex a ella he \\
vull anar a tu en tal \\
condició que tu ames \\
a mi". \\
\end{tabular} & $\begin{array}{l}\text { Però ell, despuys, } \\
\text { mentí a la dita } \\
\text { ymatge, car pres } \\
\text { per muller la dita } \\
\text { fadrina de qui ell } \\
\text { ere enemorat. I/ E } \\
\text { l'escolà, cuydant- } \\
\text { se que fos alcuna } \\
\text { fantasma... }\end{array}$ \\
\hline $\begin{array}{l}\text { Recull d'exemples } \\
\text { i miracles ordenat } \\
\text { per alfabet (650), } \\
\text { de Arnau de Lieja: } \\
\text { "Eximpli de un hom } \\
\text { jove qui acomanà un } \\
\text { anell seu a la ýdola } \\
\text { Venus". }\end{array}$ & Prosa catalana. & $\begin{array}{l}\text { Tubach: } 4101 \text { (Ring } \\
\text { given to Venus) } \\
\text { Thompson: T376 } \\
\text { Poncelet: -- }\end{array}$ & $\begin{array}{l}\text { en la ciutat de } \\
\text { Roma... }\end{array}$ & $\begin{array}{l}\text { un jove qui } \\
\text { novellament havia } \\
\text { pres muller... }\end{array}$ & $\begin{array}{l}\text { una ymatge de una } \\
\text { ýdolla de aram } / / \text { une } \\
\text { fembre vestida de } \\
\text { vestedures de fembre } \\
\text { de bordell [...] ten } \\
\text { primes que li parien } \\
\text { les carns e feya los } \\
\text { gests e los continents } \\
\text { desonests. }\end{array}$ & & $\begin{array}{l}\text { jaent en un lit ab sa } \\
\text { muller, sentí entre ells } \\
\text { una spessura [...] los } \\
\text { embargava que no-s } \\
\text { podien acostar la un } \\
\text { a l'altre. }\end{array}$ & $\begin{array}{l}\text { trobà e veé que la } \\
\text { ymatge tenie lo puyn } \\
\text { estret de lla man del } \\
\text { dit en què tenie lo } \\
\text { anell // la dita neula } \\
\text { los embargava [.... E E } \\
\text { lo qual hom jove oý } \\
\text { una veu... }\end{array}$ & $\begin{array}{l}\text { E de aquella ora } \\
\text { avant, se poch acostar } \\
\text { carnalment ab sa } \\
\text { muller, axí con feyia } \\
\text { abans que hagués } \\
\text { acomanat lo dit seu } \\
\text { anell a la dita ýdola } \\
\text { Venus. }\end{array}$ & & $\begin{array}{l}\text { Segons que recompte } \\
\text { Guillem... // ýdola } \\
\text { Venus // "neula" entre } \\
\text { la pareja // Palamo, } \\
\text { qui savia de l'art } \\
\text { de nigromancaia // } \\
\text { desfile de demonios // } \\
\text { "premio final". }\end{array}$ \\
\hline $\begin{array}{l}\text { Liber Mariae } \\
\text { (XVI.5.9), de } \\
\text { Gilde Zamora: } \\
\text { "Miraculum nonum } \\
\text { quinti tractatus } \\
\text { est de clerico qui } \\
\text { uxorem et omnia } \\
\text { reliquit propter } \\
\text { beatam virginem". }\end{array}$ & Prosa latina. & $\begin{array}{l}\text { Tubach: } 5148 \\
\text { (Variante a : Virgin } \\
\text { speaks to a devot } \\
\text { clerk) Thompson: } \\
\text { T376.1 } \\
\text { Poncelet: } 866\end{array}$ & $\begin{array}{l}\text { In territorio civitatis, } \\
\text { quae dicitur Pisa... }\end{array}$ & $\begin{array}{l}\text { erat quidam } \\
\text { clericus [...] reginae } \\
\text { servitium devota } \\
\text { mente reddebat, } \\
\text { horasque diei quae } \\
\text { tunc temporis } \\
\text { a paucissimis } \\
\text { dicebantur in ejus } \\
\text { honorem sedule } \\
\text { decantabat. }\end{array}$ & $\begin{array}{l}\text { apparuit ei sancta } \\
\text { Dei genitrix, et ei } \\
\text { serena voce dixit: } \\
\text { "O stultissime } \\
\text { hominum, cur me } \\
\text { dereliquisti?..." }\end{array}$ & $\begin{array}{l}\text { Venientes autem } \\
\text { amicic ejus ad eum } \\
\text { insistebant ut tediret } \\
\text { ad propria, et uxorem } \\
\text { ducens honorum } \\
\text { curam gereret } \\
\text { paternorum. }\end{array}$ & $\begin{array}{l}\text { Itaque ex more } \\
\text { nuptias celebrarunt } \\
\text { cum grandi } \\
\text { laetitia. Nocte vero } \\
\text { sequenti ingressus } \\
\text { cubiculum cum } \\
\text { uxore, ignorantibus } \\
\text { cunctis, clam domum } \\
\text { egressus... }\end{array}$ & & $\begin{array}{l}\text { clam domum } \\
\text { egressus, tam } \\
\text { uxorem quam omnia } \\
\text { quae habere potuit } \\
\text { dereliquit. [...] Nemo } \\
\text { tamen ambigere } \\
\text { dicitur quod ipsius } \\
\text { sanctae coeli reginae } \\
\text { sit protectus... }\end{array}$ & $\begin{array}{l}\text { "O stultissime } \\
\text { hominum, cur me } \\
\text { dereliquisti? Cum } \\
\text { amica tua essem, } \\
\text { illaqueatus alterius } \\
\text { amore, numquid } \\
\text { alteram invenisti } \\
\text { meliorem?". }\end{array}$ & \\
\hline $\begin{array}{l}\text { Liber Mariae } \\
\text { (VII.14.1), de Gil de } \\
\text { Zamora: "Legitur } \\
\text { quidem inter } \\
\text { miracula eiusdem } \\
\text { virginis, quod in } \\
\text { ungaria quidem } \\
\text { extitit rex henricus". }\end{array}$ & Prosa latina. & $\begin{array}{l}\text { Tubach: } 5148 \text { (Var. a) } \\
\text { Thompson: T376.1 } \\
\text { Poncelet: } 964\end{array}$ & In ungaria. & $\begin{array}{l}\text { Clericus vero, cum } \\
\text { iam esset peritus et } \\
\text { diaconus ordinatus, } \\
\text { incurrit egritudinem } \\
\text { vehementem, a qua } \\
\text { liberavit eum almiflua } \\
\text { virgo, ex ex quod } \\
\text { eidem devotissime } \\
\text { precinebat et suam } \\
\text { eidem declinaverat } \\
\text { castitatem. }\end{array}$ & $\begin{array}{l}\text { none antiphonam } \\
\text { persolveret, videlicet } \\
\text { Pulchra es et decora, } \\
\text { filia iherusalem; } \\
\text { eidem cum duobus } \\
\text { angelis apparuit, et } \\
\text { apparens talia intulit } \\
\text { alma virgo. }\end{array}$ & $\begin{array}{l}\text { quod frater suus } \\
\text { obiit qui regnum } \\
\text { ungarie gubernabat; } \\
\text { et barones loco eius } \\
\text { in regem violenter } \\
\text { prefatum clericum } \\
\text { coronarunt, ipsumque } \\
\text { [nupcias] contrahere } \\
\text { compulerunt. }\end{array}$ & & & $\begin{array}{l}\text { regis filius, } \\
\text { contemptis carnalibus } \\
\text { nupciis, clam ivit ad } \\
\text { aquilexam civitatem, } \\
\text { in cuius pago, supra } \\
\text { ripam cujusdam fluvii } \\
\text { per septem annos } \\
\text { eremiticam vitam } \\
\text { duxit. }\end{array}$ & \begin{tabular}{|l} 
"Si ego, inquit, \\
pulchra sum, [ut] tu \\
asseris, et decora, \\
quid est quod amorem \\
meum despicis, et \\
amore carnali alteri \\
copularis? Numquid \\
non ego pulchrior sum \\
quam illa? Ubi vidisti \\
aliam pulchriorem?".
\end{tabular} & $\begin{array}{l}\text { El clérigo es hijo } \\
\text { del rey Henricus de } \\
\text { Hungría. Se subraya } \\
\text { la importancia de la } \\
\text { castidad: "Recordare } \\
\text { quod tuam mihi } \\
\text { castimoniam } \\
\text { devovisti...". }\end{array}$ \\
\hline
\end{tabular}

